\title{
Topics and trends in finance research: what is published, who publishes it and what gets cited?
}

Article

Accepted Version

Creative Commons: Attribution-Noncommercial-No Derivative Works 4.0

Brooks, C. and Schopohl, L. (2018) Topics and trends in finance research: what is published, who publishes it and what gets cited? The British Accounting Review, 50 (6). pp. 615637. ISSN 0890-8389 doi:

https://doi.org/10.1016/j.bar.2018.02.001 Available at https://centaur.reading.ac.uk/75372/

It is advisable to refer to the publisher's version if you intend to cite from the work. See Guidance on citing.

To link to this article DOI: http://dx.doi.org/10.1016/j.bar.2018.02.001

Publisher: Elsevier

All outputs in CentAUR are protected by Intellectual Property Rights law, including copyright law. Copyright and IPR is retained by the creators or other copyright holders. Terms and conditions for use of this material are defined in the End User Agreement.

www.reading.ac.uk/centaur 
Central Archive at the University of Reading

Reading's research outputs online 


\title{
Topics and Trends in Finance Research: What is published, who publishes it and what gets cited?
}

\author{
Chris Brooks* and Lisa Schopohl
}

ICMA Centre, Henley Business School

January 2018

\begin{abstract}
In this study we provide a detailed examination of the subject matter of finance research and its institutional features as it has evolved over the past two decades. Drawing on novel approaches from data science, we examine the content of more than 30,000 published papers. Overall, we find a striking lack of diversity in the topics investigated and the methodological approaches used. Almost all finance research is conducted using techniques from economics and mathematics, with virtually no use made of qualitative methods or interdisciplinary approaches. Looking at the developments of the discipline over time, we document an increase in the volume of corporate finance research and a variation in the topics covered following the financial crisis, although these changes appear to be reactive and trivial rather than paradigm shifts. We also provide a cartography of research in finance and its citation-based impact by the location of authors. Leading finance research is concentrated in elite US institutions, and has a disproportionately strong citation-based impact. Compared with other business and management sub-fields, citations in finance are heavily skewed towards the top journals as the latter generate almost twice as much impact as the lower rated outlets.
\end{abstract}

Keywords: research topics in finance; citation analysis; journal ratings lists; $A B S$ list; critical finance. J.E.L. Classifications: A11, B41, O30

Corresponding author: Chris Brooks, ICMA Centre, Henley Business School, University of Reading, Whiteknights, Reading RG6 6BA, UK; tel: (+44) 118378 7809; e-mail: C.Brooks@reading.ac.uk

Acknowledgements: We are grateful to Rohan Brooks for co-writing the Python code that enabled us to conduct the analysis in the paper, and to Karen Rowlett for her support with obtaining data from Scopus and SciVal. We thank Adrian Bell for very helpful comments on a previous version of this paper. 


\section{Introduction}

As a scholarly field of enquiry, finance has developed rapidly over the past 30 years - both in terms of the volume of published work and its quality (Ashton et al., 2009, p.205). As a sub-discipline it now holds a credible position in business schools and social science faculties globally. ${ }^{1}$ Considering it a subfield of economics, Kelly and Bruestle (2011, Table 3) show that the number of papers published in financial economics grew by $69 \%$ between the 1970 s and the 2000 s, so that it ended their sample period as the single most voluminous of 27 sub-fields across the economics area. Yet it is a relatively new subject argued to have emerged as an identifiable sub-discipline in the early 1900s (Sweetser and Petry, 1981). Perhaps as a result of its relative youth, it lacks the critical perspective and self-evaluatory streams of literature that characterise related sub-fields such as accounting and economics (Weir, 2014). While accounting has a long tradition of vivid discussions about the route of research progression and research paradigms (e.g., Beattie, 2005; Beattie and Goodacre, 2004; Brown et al., 2007; Laughlin, 2007), much less self-reflection is found in the finance academic community. Given the size and stature of the research area, however, a more thorough and up-to-date introspective evaluation of the characteristics of finance publishing is now surely overdue.

Similar to other research areas, scholars in finance operate in a largely autonomous environment where they are free to identify their own research agendas and to determine the appropriate methodologies and data sources to tackle them. As a result, the body of published research output will reflect the summation of all of these choices made by individual researchers, and it is pertinent to question the kinds of outcomes that the process leads to in terms of the topics covered, the methodologies employed, the prior work cited, and the outlets it appears in. Decisions about what to work on and where to publish it will arise from the juxtaposition of several factors (see the discussion in, for example Whitley, 2000 and Woolgar, 1988): intellectual curiosity, serendipity, a desire to influence policy or practice, and incentive structures relating both to prestige and academic performance management.

Although a reasonable number of studies have examined which topics are favoured for scholarly enquiry in economics (e.g., Kelly and Bruestle, 2011; Kim et al., 2006; Kosnik, 2014) and in areas of accounting (e.g., Beattie, 2005; Hesford et al., 2006; Merchant, 2010), little such analysis has been undertaken for finance. Existing studies are limited in number and scope, typically covering a handful of elite journals over a short range of time. A relevant study is by Borokhovich et al. (1994a), who report that during 1990-1991, just over half of all the research in eight leading finance journals was in the financial markets area, thirty percent was on corporate finance, and fifteen percent on financial

\footnotetext{
${ }^{1}$ By contrast, the volume of work produced in its most cognate related area, accounting, declined since 2000 (Brown et al., 2007)
} 
institutions. Relatedly, the work by Borokhovich et al. (1994b) is focused on identifying the most cited studies in finance and classifying them into one of three subject areas. A more recent study by Borokhovich et al. (2016) also shows that the number of corporate finance articles has increased over the past two decades, although the authors do not investigate whether this growth is merely in absolute terms or relative to other broad areas within finance. Tellingly, they find that elite generalist journals are more influential in corporate finance research than the specialist journal in precisely this field.

Taking a narrower perspective, Netter et al. (2009) document the increasing dominance of corporate governance within corporate control research, while Keloharju (2008) focuses on the subject matter of the most cited 200 papers, with financial markets making up $40 \%$ of the citations, corporate finance and governance $20 \%$, and financial institutions and services $10 \%$ (others comprise the remaining $30 \%$ ). In a related previous study, Arnold et al. (2003) find that besides methodological papers, the top cited finance studies in 1990-1999 are on topics of corporate finance as well as asset pricing and investment. Interestingly, Borokhovich et al. (1998) show that different business schools appear to specialise in different fields of finance, and articles in the "general finance" area appear to predominate in more prestigious journals, while research on financial institutions appears in less influential outlets.

Equally as relevant as the topics that finance scholars have been investigating are the questions of where this research gets published, who publishes it and, perhaps most importantly, what research in finance has the strongest impact on the discipline. One common measure of the impact of scholarly output is the number of times a publication is cited by other researchers. Conversely, the impact of an academic journal is commonly approximated by the aggregate number of citations of all papers that they published over a particular time period. Hence, citation patterns not only affect the decisions of researchers in terms of where to submit their study for publication but the potential for generating citations is also likely to enter the decision making process of editors when deciding which papers to accept for publication and which to reject. Thus a deeper understanding of citation patterns in finance and especially the relative difference between the impact of publications in the top rated finance journals vis-à-vis the lower rated outlets not only provides us with a snapshot of the current state of publishing in the field but also serves as a potential indicator for the future development of research and publication strategies in finance.

Given the volume and importance of finance as a field of research, it is perhaps unfortunate that we know so little about it in terms of what topics are being covered, who produces the research and what research has the strongest impact on the discipline as measured by citations. A re-examination of these issues is highly warranted and we argue that, for several reasons, it is of great importance for the field of finance to extend this line of enquiry and to provide an up-to-date assessment of the kinds of 
research that are produced in finance and the institutional environment they operate within - not only in specific areas or a sub-set of publications but across the broad spectrum of journal quality dimensions. First, although finance is a relatively young sub-field within the social sciences (Alexander and Mabry, 1994) and while it has close links to the areas of economics and accounting, it has emerged as an independent research area - with its own agenda, methodological approaches and official bodies - and accounts for a large share of the research produced at business schools (Horrigan, 1987; Ashton et al., 2009). Second, for finance to grow as a sub-field and to make important contributions to our understanding of financial markets it is essential to know which areas are thoroughly investigated and which areas are less well understood in order to shape future research agendas. Third, the number of finance journals has grown markedly over the past two decades and so has the number of papers published within each of them. It is essential that studies of activity in finance publishing are comprehensive rather than merely discussing a small sub-set of elite journals that cite only their own and each other's work (see Lee and Williams, 1999). Fourth, performance management in universities has become more formalised and the development of citation indices, journal ratings, and institutional rankings have facilitated comparisons and encouraged greater focus on the place of publication rather than merely the subject matter (Willmott, 1995; Willmott, 2011; Agyemang and Broadbent, 2015; Tourish and Willmott, 2015). The most prevalent journal ratings list in the UK is produced by the Association of Business Schools (ABS) and we rely on it to classify journals into different quality dimensions. ${ }^{2}$ Fifth, and more narrowly, for early career researchers and those outside the academy who make use of its finance outputs (e.g., financial market regulators, central bankers, hedge fund analysts), it is instructive to know which subject areas and specific topics are covered in journals of different ratings, how these patterns have changed over time and which publications attract the largest number of citations. Finally, contemporary databases of bibliometric information and abstracts, as well as the programming tools to conduct the analysis that were not previously available, allow us to investigate a richer set of questions than would have been possible to consider in the past.

Our paper seeks to address a number of high-level questions about the nature of research that has been conducted in finance over the past two decades and the institutional features of finance research including the institutions where it is produced and the journals where it is published, specifically:

1. What are the broad subject areas within finance that research fits into? Does this vary according to the perceived quality of the journal it is published in? This strand of our research

\footnotetext{
${ }^{2}$ The journal ratings list was most recently updated in 2015 and renamed the Chartered Association of Business Schools' Academic Journal Guide. Note, however, that we are not attempting to pass judgement on the use of journal rating lists in performance management or research quality evaluation - rather, we simply use the ABS list as a convenient way to broadly categorise journals into a ranking of prestige that many researchers would agree with.
} 
adds to and updates existing findings, discussed above, in this area, particularly given our novel focus on separating the information by journal rating.

2. What methodological approaches are being used in conducting finance research? To what extent does this change by journal quality rating? This, to the best of our knowledge is entirely new analysis.

3. Within the broad classifications of subject areas, what specific topics are the focus of research in finance and has this changed over time? More specifically, did the advent of the global financial crisis affect the nature of the research conducted? Again, as far as we are aware, we are the first to conduct this analysis.

4. Which countries are producing most research in finance, and how does this compare with the relative presence of these countries in other sub-fields of business and management? To what extent is the research published in the leading journals in finance concentrated within the highest rated universities? This aspect of our study updates existing research, discussed below.

5. How high are citation counts in finance relative to other sub-fields and are there any differences in the concentrations of these citation counts? As far as we are aware, ours represents the first examination of this phenomenon.

To summarise our findings, first considering the subject areas that are the focus of scholarly enquiry in finance, we note the growing importance of corporate finance research, especially in the top-rated journals. We find a surprising degree of similarity in the subject areas covered in journal articles across quality dimensions; specialist fields that have no top-rated niche journals of their own such as insurance apparently find it more difficult to be represented at that level in the generalist outlets. We find stronger evidence in finance for the lack of paradigmatic diversity in the methodological approaches that has been previously documented in accounting, with the positivist approach being vastly predominant and relatedly, we uncover an almost total absence of interdisciplinary research within studies published in finance journals, in contrast to other fields among the social sciences. ${ }^{3}$ When we track the changing nature of the subject matter of finance research over time, the discipline appears to respond to real-world events - for example, we witness an increase in corporate governance research after the Enron scandal and an increased focus on systemic crises and contagion after the 2008 financial crisis.

Turning to the question who publishes the work, we show that the finance research published by the elite field journals is highly concentrated, both regarding the markets being studied as well as the affiliations of its authors, with research on markets, or written by scholars working outside of, the US

\footnotetext{
${ }^{3}$ In keeping with the view of the majority of finance academics, we do not treat the tools of financial economics and econometrics as representing 'borrowings' from other disciplines.
} 
being underrepresented. US-based research also garners an even more disproportionately large share of citations, given its share of scholarly output. Finally, the impact of finance research as measured by journals' citation-based impact factors is heavily concentrated in the top journals relative to journals of lower rank. The top rated finance journals receive almost double the number of citations compared to their lower ranked counterparts. While the relatively stronger impact of top journals is partially selffulfilling and reflects the quality of work published in these outlets, we find that the difference is more pronounced in finance than in any other area of business and management including economics.

Our research embodies several related strands of analysis. Some of these bring now rather dated analysis up to more recent times and expand the purview from a handful of "elite" journals over one or two years to cover a broad range of journals in finance over a 20 -year period. We are able to conduct a considerably more extensive analysis using a more sophisticated approach due to advances in databases and programming technology. We believe that our research has several uses. First, by comprehensively documenting the volumes of published output that have been produced in finance over a long period, we support readers - both academics and practitioners - who wish to have a broad overview of the subject areas that have formed the basis of scholarly enquiry over the past two decades. Second, by honing in on the specific topics within those broader areas, we are able to pick up changes in the trends that will enable readers to identify key emerging themes, together with gaps and under-researched areas; this will be particularly useful for early career academics in providing useful information on which topics are currently in vogue and which are now passé. Third, by providing new evidence on the concentration of research output among countries and on the focus of citations within 'elite' versus more standard journals, we are able to shed new light on the lack of breadth and, arguably, the lack of diversity of finance as a subject area. Our research has potentially important implications for the recent and future development of finance as a scholarly field of investigation, and we draw these out in the concluding section, which finishes with some suggestions regarding how the subject can find a way forward to richer diversity of approaches with a wider demographic of researchers able to make a contribution at the highest levels.

\section{What kinds of research is being published in finance journals?}

The first question we address concerns the type of research that is published in finance journals, both in terms of research areas and methodological approaches. To explore these questions, we employ Scopus, an abstract and citation database of peer-reviewed academic studies, ${ }^{4}$ and construct a

\footnotetext{
${ }^{4}$ Scopus is a database constructed by Elsevier and spans academic studies in the fields of science, technology, medicine, social sciences and arts and humanities. However, the journals included in the Scopus database are not restricted to those published by Elsevier itself. Overall, it covers more than 21,500 research outputs from
} 
database of all papers published in the finance area from 1996 to 2015. To identify publications in the area of finance we rely on the classification of journals by the 2015 ABS journal ratings list. ${ }^{5}$ The ABS list, now more formally termed the Chartered Association of Business Schools' Academic Journal Guide, is 'a guide to the range, subject matter and relative quality of journals in which business and management academics publish their research...based upon peer review, editorial and expert judgements ... and is informed by statistical information relating to citation[s]. ${ }^{6}$ While there already exists much research providing damning critiques of the negative effects of journal ratings lists (e.g., Mingers and Willmott, 2013; Tourish and Willmott, 2015; Willmott, 2011), we do not intend to add to this debate and we do not consider our approach to be contradictory to its tenor. Rather, we make use of the ABS list as a widely recognised way to separate journals by their perceived quality in a consistent fashion across many sub-disciplines.

We include papers published in journals classified as $2^{*}, 3^{*}$ and $4^{*}$ on the ABS list and we provide a special category for the so-called Journals of Distinction (JOD). The latter were formerly known as "World Elite Journals" in previous incarnations of the ABS list, are defined as "a small number of grade four journals that are recognized worldwide as exemplars of excellence within the business and management field broadly defined and including economics. Their high status is acknowledged by their inclusion as world leading in a number of well-regarded international journal quality lists." ${ }^{77}$ Overall, our sample consists of more than 30,000 papers in a total of 74 journal outlets.

In order to identify the topics of research and the methodologies being used, we construct word banks that reflect these two aspects. The subject categories are: Asset Pricing; Corporate Finance; Corporate Governance; Banking; Insurance; Microstructure; Investments and Portfolio Management. The methodology categories are: Empirical; Economic Theory; Experimental; Qualitative; Mathematical Theory. The subject area and methodological approach categories were predefined by the authors of this study based on a detailed examination of the prior literature and a selection of sample abstracts. The list was then refined following test trials in order to ensure that the largest possible share of the publications could be classified into an existing category. ${ }^{8}$

more than 5,000 international publishers (as of January 2016); see https://www.elsevier.com/solutions/scopus/content .

${ }^{5}$ We do not include $1^{*}$ journals in the analysis since the volume of research is dominated by one journal, "Corporate Ownership and Control", which constitutes $79 \%$ of all articles at this level. In the same way, we excluded "Physica A: Statistical Mechanics and its Applications" from the 2* category due to its dominance relative to the other journals of the $2^{*}$ category and its broad focus so that finance-related publications only represent a sub-section of all published output. The journals classified as JOD represent a sub-group of the $4 *$ journals.

${ }^{6}$ See https://charteredAbsoluteorg/academic-journal-guide-2015/.

${ }^{7}$ See https://charteredAbsoluteorg/academic-journal-guide-2015/.

${ }^{8}$ We are aware that our pre-selection of the categories could lead to a bias in the way that research is classified and to mitigate this, later in the paper we conduct a separate exercise where we let the data speak freely. 
The banks for each category include around 30 to 50 words or groups of words, and were formed via a manual search of a random sample of titles, abstracts and keywords from journals across all quality ratings. For example, 'CAPM' clearly fits best in the Asset Pricing category, while 'IPO' fits squarely under the 'Corporate Finance' heading. Any search terms which are potentially ambiguous from the perspective of the type of work they describe are discarded.

Using code which we wrote specifically for this task in Python, we perform a count of the number of words/word groups in each category and the article is deemed to be in the category which has the maximum number of word hits. Using these word banks to search through the abstracts and keywords (if the latter are listed in the database) and summing the hits together across abstracts and keywords, we are able to classify the articles by the topic of the research and by the broad type of methodology, although there are still some studies that we are unable to classify in this fashion: approximately $10 \%$ of searches result in no word matches; $10 \%$ in a tie between two or more categories (which we discard) and $3 \%$ of articles have no abstract available.

Results for the articles classified are presented in Table 1 with subject areas in Panel A, methodological approach in Panel B, and the cross-section of subject area and methodological approach in Panel C. On the whole, we find a considerable degree of similarity in the broad subject areas covered by the various outlets across journal quality measures. Around $33 \%$ of papers are in the asset pricing area, roughly $20 \%$ on corporate finance, around $10 \%$ on corporate governance, $15 \%$ on banking, $5 \%$ on insurance, $8 \%$ on microstructure, and $10 \%$ on investments and portfolio management. Corporate finance is considerably more popular in the elite journals (4* and JOD), with approximately double the percentage of work in that area compared with $2^{*}$ and $3^{*}$ journals. By contrast, work on insurance is almost entirely absent from the leading journals, it usually being considered a specialist area but having no top-rated journals of its own. It is rare for focused journals to achieve the highest ratings (with perhaps the Journal of Financial Intermediation, uprated from $3^{*}$ to $4 *$ in the 2015 revision to the ABS list constituting the only exception under the finance heading). This limits the scope for relatively specialist research (e.g., on real estate or insurance) to be published in the elite journals and privileges work that fits in what would be considered the disciplinary core, such as corporate finance.

We also repeat the same analysis separately for each sample year, and find surprisingly little change over time. The second and third rows before the end of the table report the averages for the sample split into two halves: 1996-2005 and 2006-2015. We observe a four percentage point decline in the volume of asset pricing work, with two percentage point increases each for corporate governance, for banking, and for insurance. Our findings are in line with those of Borokhovich et al. (1994a), computed using a much shorter and earlier time period, who find financial market studies and corporate finance 
research to dominate the research agenda in North-American finance departments, although the relevance of corporate finance research has considerably increased in our more recent dataset.

Panel B of Table 1 shows that research incorporating empirical work dominates the methodological approaches used in finance journal publications, particularly at the higher rated outlets where more than $80 \%$ of research conducts data analysis. On the other hand, papers using mathematical theory (e.g. studies developing models for the pricing of exotic options, possibly including simulations but no data analysis) are twice as common among the $2-3 *$ rated journals (25\% of work at this level) compared with the elite journals (13\% of work). Papers developing models based on economic theory (i.e., pure theory papers with no empirical work) are equally represented at all journal ratings, making up $5 \%$ of all studies classified. As for Panel A, very little change is discernible over time, and these percentages barely change between the first and second decades of our sample. We observe just a one percentage point reduction in the volume of research using empirical methods and a similar increase in the amount of work based on mathematical theory. In comparison, Kim et al. (2006) and Hamermesch (2013) both document a switch away from theoretical work and towards empirical studies in economics: in the former study, they document that $77 \%$ of highly cited papers were theoretical in nature during the early 1970 s, reducing to $11 \%$ by the end of the 1990 s. By contrast, we observe that in finance this trend had already run its course by the beginning of our sample period.

If we combine the number of studies using experimental techniques (e.g., a lab-based analysis of trading behaviour under controlled conditions) with those using a qualitative approach (e.g., interviews or questionnaires), the total volume of such studies is tiny at all quality levels, comprising less than $1 \%$ of all research categorised. Thus a positivist approach to research design using tools from mathematics, economics and/or econometrics, is pervasive in finance, with almost no use of other approaches, and the values in the final three rows of the table suggest that this situation has persisted throughout the sample period (see also Ardalan, 2000; 2003).

The dominance of data analysis as the singular methodological approach also occurs in accounting, but to a much lesser degree, with perhaps $20 \%$ of research using alternatives (Beattie, 2005, Table 3). All of the JOD in finance are edited in the US and this might explain the predominance of the positivist approach in those outlets as US based journals tend to favour a positivist research style (see Beattie, 2005, for a parallel discussion in the accounting context), but we would perhaps have expected the wider geographical spread of author affiliations at the lower rated outlets to have led to the use of a broader range of methodological perspectives, consistent with the British and indeed pan-European traditions in accounting research. Yet our results in Table 1 indicate that this is not the case for finance. The lack of paradigmatic diversity has been lamented in accounting (Merchant, 2010), but appears much more widespread and deeply embedded in finance. While we can only speculate about the 
possible reasons for the dominance of the positivist approach in finance, one potential explanation relates to the sub-field's roots in financial economics and the strong quantitative direction of the latter discipline. In addition, it might reflect a trickle-down effect as researchers initially target their work at the top-rated journals and they therefore tailor their style, approach and subject matter to cover what they believe will fit there. Only if their work is rejected by these top journals do they re-submit it to the lower rated outlets, hence transferring the paradigmatic approach favoured in top journals into the lower rated ones. In fact, this trickle-down effect might be especially strong for finance scholarship as rejection rates at the top finance journals are particularly high compared to other disciplines: a formal comparison across all 22 sub-fields used in the ABS list reveals that finance has the second lowest acceptance rate among $4 *$ journals of $6.5 \% .{ }^{9}$ Hence, as a consequence a larger share of the work that is initially targeted to the debates in top finance journals will end up in lower rated outlets.

Next, we are interested in the extent to which finance scholars engage in interdisciplinary research, i.e. research that extends beyond the sphere of finance and adopts concepts and approaches from other (social) sciences. Again, we rely on a bank of words to try to classify research that adopts an interdisciplinary approach. The results of this analysis are presented in the final column of Table 1, Panel B. ${ }^{10}$ Although interdisciplinary work may be hard to detect and thus our figures likely underrepresent it, its volume is roughly constant at a paltry $3 \%$ across the quality ratings, which can be regarded as low by all means. Our finding of a lack of cross-fertilisation from other fields adds stronger and more up to date evidence to that in prior studies. ${ }^{11}$ For instance, Burgess and Shaw (2010, Figure 3) find that finance and economics journals are less connected to any other sub-fields, evidenced by virtue of having no journal editorial board members in common, perhaps because the methodological approach is so highly specialised. Finance is also found to be less interdisciplinary than most other social sciences, including accounting, and only $12 \%$ of citations in finance publications are to work outside of finance or economics (Borokhovich et al., 1994a). This compares with half for accounting (Bricker, 1993), anthropology (half of research from other fields), political sciences (half), psychology (27\%), sociology (42\%) and even economics (22\%) - all percentages from Rigny and Barnes (1980). According to Borokhovich et al. $(2015$, p.9), only the two highest rated finance journals have a

\footnotetext{
${ }^{9}$ This compares with $9 \%$ and $9.5 \%$ for economics and accounting respectively, the two most cognate disciplines to finance; only International Business and Area Studies has a slightly lower acceptance rate than finance, at $6 \%$. The figures have been obtained from a search of the websites of the journals for each ABS subfield and complemented with data obtained from directly contacting the editors (in chief, or their secretary), in case this data was not available on the journal website.

${ }^{10}$ Within the word bank for interdisciplinary research, we include terms that capture other subjects that finance could potentially draw ideas and approaches from, such as sociology, psychology, and law as well as generic terms such as interdisciplinary.

${ }^{11}$ Beattie and Goodacre (2004) argue that the level of 'interdisciplinary borrowing' is high in both accounting and finance; however, this statement is based on the classification of economics as being a sub-field. However, most finance specialists would argue that financial economics is very much in the core of finance and thus they would not consider the use of economic tools in financial research to be evidence of interdisciplinarity.
} 
significant reach into other social sciences and all of the top journals in social sciences by impact factor are from the psychology discipline, although all six journals that they investigate have extensive citations in accounting and economics.

As a final strand of this analysis, Panel $\mathrm{C}$ of Table 1 splits the percentage of work for each subject area according to the methodology used. It is clear that corporate finance and microstructure make the most use of the empirical approach using secondary data, and asset pricing makes the least use of qualitative methods. By contrast, in the corporate governance area, $1.7 \%$ of the work is qualitative, and just over $10 \%$ uses mathematical theory models; here, over $8 \%$ of the work is identified as interdisciplinary, by far the highest among subject classifications.

\section{What are the trends in finance research topics?}

One potential concern with the above analysis is that, by pre-specifying the list of terms to include in the word banks, we are imposing our own subjective judgements on the classifications of studies in defining the categories, and this might affect the results. To address this concern and to complement our previous findings, we examine the keywords assigned to a paper by the authors of that work at the time they wrote it in order to identify patterns and trends in finance research both across time and journal outlets. This analysis also provides a clearer picture of the kinds of topics that are investigated within the different subject areas and the specific methodological approaches that are used. We focus on keywords as they are more representative of the topics and intended contributions from the perspective of the author. However, in unreported results, we repeated the analysis for the most commonly used words in the abstracts of papers. ${ }^{12}$ To the best of our knowledge, such a textual analysis to uncover trends in finance research is novel to the literature.

Using the same sample of papers as in the previous analysis (Table 1), we identified the 300 most commonly used keywords assigned to the papers. ${ }^{13}$ We filtered out generic terms from the list that do not reflect field-specific terminology and thus do not allow us to deduce any patterns in the topics covered by finance researchers. ${ }^{14}$ We convert all English spellings to their US equivalents, and all plurals into their singular forms to avoid separate counts being formed (e.g. 'IPOs' becomes 'IPO'). ${ }^{15}$

\footnotetext{
${ }^{12}$ These results are not presented since the findings are broadly similar but less sharp than those derived from the keywords.

${ }^{13}$ Due to the design of our search algorithm, we count each word separately so that a keyword composed of several words is counted by each component of the keyword, e.g. the keyword "efficient market hypothesis" would be counted under "efficient", "market" and "hypothesis".

${ }^{14}$ Examples of such generic terms include "effect", "explanation", "equation", "problem" etc. We also filtered out JEL classification codes as they are only available for a small subset of the sample.

${ }^{15}$ The latter using the 'singularize' command in the 'inflection' Python package.
} 
Due to the growing number of papers published in finance journals and covered in the Scopus database, we observe a strong upward trend in the number of times each specific keyword is mentioned over time. To account for this trend and to ensure that valid comparisons can be made across the years, we normalise the number of occurrences of a specific keyword by the total number of occurrences of all such terms among the 300 most commonly cited keywords in the period of investigation.

To provide a first overview of the spectrum of keywords across different journal quality dimensions, Figures 1-4 depict the 300 most commonly used keywords, weighted by their number of occurrences over the period 1996-2015 of the JOD, 4*, 3* and $2 *$ journals, respectively. A striking feature of these four word clouds is the broad similarity of the dominant keywords across different quality dimensions, although the relative weight differs by journal category. For instance, while "corporate" finance and "governance" issues in particular represent two of the most important areas of enquiry in JOD and $4 *$ journals more broadly, they are far less dominant in the $2^{*}$ category and do not rank among the most widely researched topics in 3* journals. In comparison, research on "risk" is the single most dominant area in $3^{*}$ journals, while also featuring quite prominently in JOD and $2 *$ outlets. It seems evident that the lower rated $\left(2^{*}\right.$ and $\left.3^{*}\right)$ journals tend to focus more on models and instruments as the core of the study; the higher rated journals, on the other hand, are usually more concerned with the applications so that the techniques and data are merely a means to an end. Thus perhaps a key differentiator that we observe by journal quality is the strength and importance placed on the interpretation of results as testing financial theories.

While the word clouds in Figures 1 to 4 provide a first visualisation of the relative importance of certain research topics in finance, they do not allow a more formal analysis of the dominant topics and trends over time. To complement these graphical presentations, panels A and B of Table 2 list the 20 most commonly used keywords together with the share of counts across all 300 keywords, both for different journal ratings (Panel A) and over time (Panel B). As can probably be expected, generic terms such as "risk", "stock", "equity" and "market" rank highly among the top 20 keywords across all journal qualities as well as over time. In addition, there is a considerable overlap among the most commonly used keywords across the different journal classifications, confirming our prior finding of a high similarity of research topics across journal quality dimensions. However, a closer look at the results reveals interesting differences in the most popular topics across different journal qualities. While studies related to "risk" are highly popular in the top outlets (JOD and $4 *$ journals), their relative representation in the lower ranked journals ( $3^{*}$ and $2^{*}$ ) is considerably stronger, accounting for $5.12 \%$ and $4.18 \%$ of all counts for $3^{*}$ and $2 *$ journals, respectively. In addition, "corporate" finance related terms and research on "governance" issues is highly featured in JOD, $4 *$ and $2^{*}$ journals - ranking in 
the top 5 keywords for these outlets - while it is far less common in the $3^{*}$ category (positions 10 and 14, respectively). This is in line with the findings from Table 1 and Figures 1-4. Topics related to "liquidity" are popular in top journals and 3* journals while they are absent from the most commonly used keywords in $2^{*}$ journals. In comparison, $2^{*}$ journals are the only ones where topics related to "insurance" (position 10) and "social" factors (position 14) rank among the most common research areas by keyword, suggesting that these areas have not entered the mainstream of finance research in the highly ranked journals. Again, these findings raise questions regarding the ability of specialist fields (e.g. "insurance") and more interdisciplinary work ("social") to enter the most prestigious outlets and they confirm concerns that - given the importance of publications in top journals for career progression - early career researchers might be discouraged to enter these fields in the first place. Finally, "bank" and "banking" related topics appear to be particularly dominant in non-JOD 4* and 3* journals, with the term "bank" scoring in the top five keywords for these journal outlets.

Turning to the patterns of the top 20 keywords over time (Panel B), we notice some interesting shifts in the dominant topics of finance research that provide an insight into the driving forces that shape the finance research agenda. Firstly, research on "efficiency" (of markets and market mechanisms) one of the defining themes of modern finance and a cornerstone of many financial theories and models - has been in decline over time and has dropped from the list of most commonly used keywords in the 2011-2015 sub-sample. While we can only speculate about the causes of this shift, the decline of "efficiency" and the emergence of alternative models to understand financial markets (e.g., based on behavioural finance) might represent a change in the understanding of and approach to the field, allowing for a more multifaceted concept of finance. Secondly, the emergence of "corporate" finance research and in particular "governance" related topics in the 2000s as well as the strong interest in research on "crisis" and "default" in the 2011-2015 period are interesting phenomena, given the historical backdrop of events (e.g., the Enron governance scandal and the global financial crisis, respectively). This is in line with findings by Netter et al. (2009), who documented a strong increase in research on governance issues relative to other corporate control mechanisms beginning in the mid1990s and growing through the 2000s.

Questions have been raised about whether the response of the academic finance community to the global financial crisis has been sufficient (Gendron and Smith-Lacroix, 2015), as it appears from the outside as if it has been very much 'business as usual' for scholars, continuing their work as if nothing had happened and relatedly, Brooks et al. (2017) argue that scholarly finance research is excessively elitist, failing to engage sufficiently with real-world problems. By examining changes in the subjectspecific words used in abstracts and author-selected keywords, we are able to provide evidence to test this conjecture. Our findings seem to suggest that finance research might be responding to real-world 
events (albeit with a time lag). For instance, the Enron accounting scandal in the early 2000 s puts the spotlight on the importance of governance mechanisms in corporate structures and seems to have triggered a body of research aiming to understand the role that governance plays in the workings of firms. In addition, the growth in the popularity of "crisis" and "default" as keywords and the corresponding research into these areas was presumably triggered by the 2008 Financial Crisis and, one might hope, represents attempts to understand the origins of the crisis and its consequences for financial markets and the wider society. These two developments are particularly interesting against the backdrop of Mackenzie's (2006) argument that finance research serves as "an engine of inquiry rather than a camera to reproduce empirical facts" and they draw into question the extent to which finance research is still shaping realities or merely responding to and attempting to explain what is happening in the real world. Moreover, although on the surface the global financial crisis made a considerable difference to the subject matter of academic research in finance, it appears to be the case that researchers have continued to operate in largely the same paradigms and methodological frameworks, with the post-crisis era being treated as a sub-sample test rather than an opportunity to develop a radically new approach (see Colander et al., 2009 for a similar critique of research in economics).

Panel $\mathrm{C}$ zooms in on the most commonly used words in the abstracts of finance publications across different subject areas, as identified in Table 1, and hence allows a comparison of the research agendas in different sub-disciplines within finance. Overall, the dominant words reflect the focus of each subject area and hence provide additional support for our identification strategy used in Section 2. It also indicates some interesting similarities among subject areas and suggests which sub-fields are more closely related than others. Corporate governance research, for instance, shares the lowest number of common words with any other sub-area, having often less than half of the words in common with other areas. The lowest match exists for asset pricing and corporate governance studies, whereas the greatest overlap in common words can be found between asset pricing studies and work in the areas of microstructure and portfolio management and investment. Interestingly, research in the area of portfolio management and investment has a majority of words in common with all other sub-fields, suggesting that it brings together different streams of finance research and/or borrows insights from a variety of finance streams.

While Panel B of Table 1 already suggests some interesting time trends in the most dominant areas of finance research, we investigate the changing pattern of research interest in finance more thoroughly by focusing on the 20 keywords that have seen the strongest increase over time (Table 3) and those that have seen the strongest decline (Table 4). Table 3 ranks the keywords by their highest average rate of change from one sub-period to the next and hence allows a comparison among the most 
trending finance topics across different journal qualities. ${ }^{16}$ The figures confirm some of the trends seen in Panel B of Table 2 such as the strong increase in research related to "crisis" (e.g., "contagion", "systemic", "default") which is particularly strong in the $3 *$ journals and the JODs. These topics also account for some of the largest absolute changes in representation from 1996-2015 (e.g., "crisis" increased by 0.97 percentage points across all journals while it saw an absolute increase of 1.35 and 1.13 percentage points in JODs and $3 *$ journals, respectively). In addition, the $2 *$ journals and the (nonJOD) 4* journals experienced a growth in topics around "political" and "social" issues over the entire period, while they were among the most trending topics within JODs only in the last sub-period of the sample. It is still too early to assess what this means for the research agenda in finance and more detailed analysis is needed to formally interpret these findings, but these trends might be indicative of tendencies towards more interdisciplinary approaches and/or a gradual broadening of the research agenda which finance has been lacking over the last decades as the evidence in Section 2 suggests. Asset pricing-related research around "arbitrage", "premium", "predictability", and "anomalies" is trending in top journals (JOD and to a lesser extent 4 * journals), while research around "risk" and risk modelling has been one of the most trending topics in $3^{*}$ journals, reinforcing the focus at this level on quantitative finance and mathematical approaches (see Table 1). $2^{*}$ journals are increasingly focused on different "stakeholders" ("director", "board", "investor", "shareholder"), and particular market segments such as "China", "emerging" markets, and "Islamic" finance. Interestingly, different markets (and market segments) do not seem to feature in higher ranked journals, potentially indicating a lack of geographical diversity in their research - a pattern that we will explore in the next section.

Table 4 focuses on the keywords that have seen the greatest decline over the period 1996 to 2015 . In the top journals (JOD and $4 *$ ), topics around market "microstructure" (e.g. "bid-ask", "spread") as well as equity issuance (e.g. "offering", "seasoned", "offer", "tender") have declined particularly rapidly. However, we have to be cautious in drawing too strong a set of conclusions from this finding. A nuanced analysis of these patterns reveals a more subtle shift of focus within these strands of enquiry. For instance, while research in microstructure investigating liquidity measures centred on bid-ask spreads appears in decline, we observe a growing interest in the relation of liquidity to systemic risks. In addition, despite the vitality in research on corporate finance overall, certain topics have gone out of vogue, perhaps reflecting a reduction in market activity in this area and therefore a decline in both practitioner interest in the topics and also a reduction in the sample sizes available for new data

\footnotetext{
${ }^{16}$ To narrow down the group of keywords and to focus on those that are fairly highly represented across journals, for this part of the analysis we only included keywords that accounted for at least $0.33 \%$ (i.e. $1 / 300$ ) of the total count across all keywords. For cases that are not present in the list of a particular sub-period but appear in other sub-periods we replace the missing share in counts with the proportion of total counts of the keywords with the lowest number of counts. Thus, the resulting changes calculated from these figures represent a conservative estimate of the actual increase or decline of the keyword.
} 
analysis. Specific econometric techniques that are more commonly used in the quantitative financedominated 3* journals have also seen a decline (e.g. "Martingale", "cointegration") and have been replaced by other techniques (see Table 3: "copula", "Lévy").

Again, the $2^{*}$ journals show the most different pattern in declining topics compared to the other journal categories. While we see some trends that are also present in other journals (e.g., a decline in issues around "microstructure", "offering" and specific techniques such as "garch" and "cointegration"), the topics that have been in strongest decline relate to research on particular market segments, e.g. "Japanese" and "Hong Kong". Interestingly, the 2* category is also the only one that features keywords of alternative markets to those of the US (see, in contrast, "nyse" and "nasdaq" among the JOD and the $4^{*}$ ), indicating that such journals serve as the outlets for research outside of the US markets.

\section{Whose research gets published in finance and whose gets cited?}

In this section, we investigate which authors of which institutions publish the work that appears in finance journals and whose work gets cited by other researchers. We focus in particular on two aspects of authors' characteristics: the geographical location of their institutional affiliation and whether the institution is considered to be part of the elite universities. In the related field of economics, Kim et al. (2006) document that $85 \%$ of the most heavily cited papers in economics were written by authors based in the US, although the concentration of work within the US significantly reduced over time. As far as we are aware, there is no comparable existing research in finance, although Borokhovich et al. (2000) study the types of research that tend to garner high citation counts, finding that shorter papers and proceedings are less influential than regular articles in the leading finance journal, and publishing outside of its mainstream areas can damage a journal's citation-based impact factor.

Table 5 provides an analysis of the country locations of the authors of scholarly output by subfield. For each country or region, the left-hand columns of numbers report the percentage of all publications in a specific subfield that has been produced by authors located in a particular geographical area (the US, the UK, Europe excluding the UK, Australia \& Oceania, Asia, Africa \& South America), while the righthand columns provide information on the proportional citations that correspond to work published by authors of different geographical locations. ${ }^{17}$ The sub-fields that are depicted comprise finance, accounting, and economics while we provide average figures for the other business and management

\footnotetext{
${ }^{17}$ The percentages in a specific column for publications and citations, respectively, do not add up to $100 \%$. The residual represents the share of publications/citations corresponding to authors in Canadian institutions, which do not appear in any other category.
} 
sub-fields featured in the 2015 ABS ranking list (10 for JOD and 19 for other quality categories). ${ }^{18}$ We retrieved the institutional affiliations of the publishing authors including their geographical location from SciVal, a data analytics software provided by Elsevier and specifically designed for the analysis of academic output. ${ }^{19}$ To define the sample of scholarly outputs to be analysed, we rely on Scopus and, similar to our approach in the previous sections, we use the journal categorisation of the 2015 ABS list to define the set of publications to include for each sub-field across different quality dimensions. These sets of scholarly outputs were uploaded into SciVal, which provided us with a listing of how many of these publications are apportioned to each specific academic institution. In order to assess the geographical distribution of the publications, we aggregate the proportional share of publications across institutions of the same geographical location. As SciVal also provides the number of citations received by the sets of publications we similarly group these citations conditional on whether the cited work is produced by an author located in a US institution, a UK institution, etc. The sample is restricted to all work published in the field-specific journals between 2011 and 2015 as this is the point from which detailed breakdowns of institutional affiliations are available in SciVal.

The figures in Table 5 highlight the supremacy of the US in business and management research generally and in finance in particular. For JOD, 70\% of authors in finance have US primary affiliations, while the figure is around $6 \%$ for the UK, $11 \%$ for the rest of Europe and less than $0.2 \%$ for the whole of Africa and South America combined. Citations of work published in JOD are even more concentrated in the US at $73 \%$ for finance JODs, implying that work in top journals by US authors has more impact than work in the same journal outlets by authors affiliated to institutions outside of the US. UK authors publishing in JOD seem to be particularly underachieving in terms of citations to their work - they account for $6 \%$ of the published work yet only receive $4.6 \%$ of all citations - while authors from the rest of Europe appear to have a roughly proportionate allocation of citations given their share of scholarly outputs ( $11.1 \%$ of outputs and $11.4 \%$ of citations). Comparing across sub-fields in the JOD category, finance has the third highest concentration of publications in the US with the second highest concentration of citations.

It is not this way in all sub-fields: Chan et al. (2014) find that in business ethics specifically (excluding other areas of management) the US has been overtaken by Europe in terms of citations, while it remains the top producer of research by volume. And indeed, once we turn to journal categories of lower rank, the dominance of the US decreases, especially in the $3^{*}$ and $2 *$ journals. While US research no longer dominates as we move down the journal ratings categories, it is still heavily present. Our

\footnotetext{
${ }^{18}$ In order to preserve space while reporting results separately for each journal quality level, we report figures for the finance field alongside its closest cognate areas: accounting and economics; all other sub-fields are merged into a single categorisation.

${ }^{19}$ https://www.elsevier.com/solutions/scival .
} 
findings extend those of Chan et al. (2016), who show that even lower rated finance journals (specifically, those rated as C-grade by the Australian Business Dean Council list) have significant numbers of US researchers among their authorships.

According to our analysis, authors from UK and continental European institutions appear particularly well represented in the $3^{*}$ journal outlets - not just in finance but broadly across business and management subject areas (accounting for $14 \%$ and $28 \%$ of publications as well as $14 \%$ and $29 \%$ of citations, respectively). Interestingly, the representation of UK institutions drops again when looking at the 2* outlets only. In comparison, authors from Australia/Oceania, Asia and Africa/South America, gradually increase their proportion of publications and citations as we move down the journal quality dimension. This finding might explain why the $2^{*}$ journals are the only ones that include keywords representing markets outside the US among their most commonly used keywords, as these journals are more populated by authors from non-Western and emerging economies. It is particularly interesting to note that, not only is two thirds of research in top-rated finance journals written by scholars based in the US, the percentage of citations to papers written by US authors is even higher at $73 \%$ for JOD. It may be that US-based authors are working on more mainstream topics, which the literature suggests are likely to garner far more citations (Merchant, 2010), or it may be that they benefit from the network effect of being in the same country as most other top authors and choose to cite the work of researchers they are already familiar with (Tol, 2007). Such systematic differences between publication and citation rates across countries or journal ratings are important since citations are increasingly used as a performance measure - both for individual authors via ' $h$-indices' (defined in Section 5) and for journals through their impact factor measures (see Baldi, 1998).

The pre-eminence of the US in particular in the top finance journals is perhaps striking but certainly not a new phenomenon. Klemkosky and Tuttle (1977) show that, of the top 20 most prolific universities in core finance journal publishing, 19 were from the US, while Chan, Chen and Steiner (2002) find that only three non-US institutions are among the top 50 institutions with the highest number of published pages in finance journals and only 15 are in the top 100. In a more recent study, Keloharju (2008) documents that among the 300 most cited finance articles published within the 2000-2006 period, authors from North-American institutions accounted for $86 \%$ of the work, $12 \%$ of the work was authored by Europe-based scholars and $2 \%$ of the articles can be attributed to researchers in Asian and Latin American institutions. Thus, while our findings indicate an increasing representation of nonUS institutions in the top journals compared to these earlier studies, this shift occurs very slowly.

An interesting question emerging from the above analysis is whether a comparable concentration of publications and citations can also be observed at the institution level. In particular, given that 
publication in top journals is highly competitive with journals having rejection rates above $90-95 \%,{ }^{20}$ are some institutions better able to place their work in outlets of the highest rank? In this sense, our results extend and bring up to the present time existing findings in this area. In a pair of closely related papers, Borokovich et al. $(1995 ; 1998)$ consider the affiliating institutions of authors publishing in 16 finance journals over 1989-1993. They focus only on US schools and show that the number of both publications and citations are heavily skewed - especially the latter - with $76 \%$ of citations and two thirds of publications arising from $20 \%$ of the institutions. Production of articles and their citation rates both increase with the prestige of the author's affiliated school (Borokovich et al., 1995).

While previous research has documented that publications in finance outlets are highly concentrated among a few top institutions (e.g. Klemkowsky \& Tuttle, 1977, and Chan et al., 2002, for publications), ${ }^{21}$ little is known about whether this trend is persistent across different quality categories of finance journals. Thus, next we analyse the concentration of institutions in finance journals of different quality ratings. First, we calculate a Herfindahl-style concentration index, which is computed by squaring the proportional share of all publications (citations) within a quality category for each institution that publishes (whose work is cited) within this category and aggregating these squared values to arrive at a single index of concentration that can take values within the 0 to 100 range. The higher this index, the more concentrated the publication (citation) behaviour in these journals. In addition, we also report the share of publications (citations) that are apportioned to the $5 \% / 10 \% / 50 \%$ of institutions with the highest number of publications (citations).

Table 6 reports these different measures of concentration. ${ }^{22}$ Focusing on the publications (Panel A), the index increases as we move up the quality ranks indicating that in the top journals publications are more highly concentrated and the vast majority of work is produced by a smaller number of top institutions. This is particularly apparent when looking at the percentages of publications produced by the $5 \%$ most publishing institutions, since we find that they account for $32 \%$ of all published outputs in JOD journals while the top $5 \%$ of institutions account for only $25 \%$ of the work published in $2 *$ journals. Turning to the concentration measures for citations (Panel B), again, we find that the impact of the work as measured by the number of citations is highly skewed towards the institutions with the most highly cited outputs, indicating that this sub-group is able to generate a disproportionately strong academic impact from their work. This concentration is greater the higher the quality of the journal

\footnotetext{
${ }^{20}$ See MacDonald and Kam (2007) for a general discussion of this issue in management.

${ }^{21}$ Providing some comparative analysis, Chan et al. (2001) examine the research output published in finance journals for the top universities in the Asia-Pacific region, again finding that appearance in the leading journals is highly skewed towards a few top performing institutions, although these are not uniquely those that have traditionally had the strongest reputations.

${ }^{22}$ Affiliations stated as the National Bureau of Economic Research (NBER) and Centre for Economic Policy Research (CEPR) are excluded from the sample to avoid double counting.
} 
with almost all citations of $4 *$ journals being located in the $50 \%$ most widely cited institutions $(50 \%$ of institutions accounting for $97 \%$ of citations). Although it is already known that across the whole research landscape citations are skewed towards a small proportion of institutions (Macdonald and Kam, 2011), this finding might still be surprising since all journals at the $4 *$ (including JOD) level are highly competitive, suggesting that all of the work published there should be of the highest quality, innovative to the field and thus highly cited by the academic community. However, even in these highest rated outlets some work achieves much greater impact than the rest and the results suggest that this is related to the institution of the author (or alternatively, highly cited authors favour working at particular institutions - see also Judge et al., 2007).

To get a better understanding of the types of institutions that publish in different journal outlets, we calculated the share of publications and citations that correspond to authors of institutions that are considered to be "elite". The question as to whether such "elite" institutions are better able to place their work in top-rated finance journals and at the same time generate greater impact from it once published is not a new line of enquiry (e.g., Kim, Morse and Zingales, 2009), though previous work has not compared the representation of elite institutions across different journal quality dimensions as well as institutions outside of the US. However, Kim et al. (2009) concentrate their analysis on top journal publications by US institutions (with the exception of a few international universities) and they are interested in the development over time. In contrast, we look at a wider range of journal quality categories and include all publications, both from within and outside of US institutions. Thus, we argue that our sample is more representative of the global research community in finance than that in any comparable existing research. As the definition of "elite" (or top) universities is ambiguous, we rely on a variety of different elite groupings and rankings to capture the broad spectrum of quality rankings and dimensions. In particular, we calculate the share of publications (citations) that correspond to the US Ivy League Colleges, the UK universities that are part of the Russell Group, the institutions that are ranked in the top 100 of the Times Higher Education (THE) World University ranking (as of 2014-15), as well as the Top 200 business schools based on the QS MBA ranking (as of 2014-15) - the latter two comprising institutions from all around the world. ${ }^{23}$ Given that there are possibly more than 20,000

\footnotetext{
${ }^{23}$ The US Ivy League is composed of the eight institutions Brown University, Columbia University, Cornell University, Dartmouth College, Harvard University, the University of Pennsylvania, Princeton University, and Yale University. The UK Russell Group comprises 24 universities: Cardiff University, Imperial College London, King's College London, London School of Economics, Newcastle University, Queen Mary University of London, Queen's University Belfast, University College London, University of Birmingham, University of Bristol,University of Cambridge,Durham University, University of Edinburgh,University of Exeter,University of Glasgow,University of Leeds, University of Liverpool,University of Manchester, University of Nottingham, University of Oxford, University of Sheffield, University of Southampton, University of Warwick, University of York. We chose the 2014-15 rankings for the THE and the QS rankings as they correspond to the end of our sample period.
} 
universities in the world, ${ }^{24}$ these rankings represent an arguably elite group of institutions considered to be of the highest rank.

As can be expected, the results in Table 6 show that Ivy League colleges account for a disproportionally large share of all publications in JOD (11\% of output for only eight institutions) and their output published in JOD receives a considerable share of citations (13\%), indicating that their work overachieves in terms of the influence generated on the work of others. Strikingly, they are considerably less represented in the lower ranked outlets $\left(2^{*}\right.$ and $\left.3^{*}\right)$ accounting for around $2 \%$ of all publications and $3-4 \%$ of citations. This finding might not come as a surprise since in a well-functioning market for academic talent, researchers with the highest potential who are conducting the most original and influential work are more likely to be employed at top universities and to publish their work in the highest rated journals. Interestingly, however, this picture changes when we turn to the Russell Group, the Ivy League's UK equivalent. Even though the Russell Group is comprised of 24 universities - as compared to the eight Ivy League colleges - the former only account for $3 \%$ of the publications and $2 \%$ of citations in the finance JOD. However, their representation both in terms of publications and citations increases in the $4 *$ and $3^{*}$ categories. In particular, UK Russell Group institutions achieve double the proportion of publications and three times their share of citations in $3^{*}$ outlets as compared to JOD. Turning to the global rankings of the THE and QS, we find an almost monotonically decreasing representation of these institutions in overall publications and citations as we move down the journal quality scale. ${ }^{25}$ Taken together, these findings indicate that publishing in top journals is still mainly restricted to elite universities (especially those in the US) while institutions of lower rank are confined to the lower rated journal.

\section{Which journals are cited the most?}

While the choice of what to cite rests with the authors of the studies, not only will they select their citations based on the relevance and strength of its arguments, they are more likely to select work that is published in higher rated journals - partly under the presumption that it has been given a gold seal of approval (Judge et al., 2007), perhaps in the hope of positioning their own work within this quality banding (the so-called 'halo effect' documented as early as May, 1967), and also to take advantage of networks by citing the research of potential referees and journal editors (Jones et al., 1996). If research agendas vary systematically by journal quality, then there may be a trade-off for authors between citing work that is published in prestigious journals and work that is most relevant. Judge et al. (2007)

\footnotetext{
${ }^{24}$ The 'Ranking Web of Universities' quotes 23,729 universities - see http://www.webometrics.info/en/node/54.

${ }^{25}$ The exception being the slightly higher share of citations of work published in $2 *$ journals $(23 \%)$ than $3 *$ journals (20\%).
} 
analyse the drivers of citation rates for management articles, finding that the ranking of the journal in which an article is published has a much higher impact on the average citation rate than either the affiliation of the author(s) or the subject matter of the research. Thus, it might well be the case that research quality is more closely approximated by citations than any other proxy, or at least any objectively measurable one (Alexander and Mabry, 1994). But it is a self-fulfilling prophecy that work which authors manage to squeeze into the top journals will become more widely cited even if it is of poor quality, irrelevant or uninteresting. Moreover, the distribution of citations is highly skewed not only across journals of different perceived quality levels, but also within journals, and between researchers (Macdonald and Kam, 2011).

The results of the previous sections suggest some interesting patterns regarding elite universities' abilities to place their work in higher quality journals and to generate a greater impact from their research. In this section, we move our analysis from the individual publication level to the journal level and analyse whether, for a given quality measure, journals in certain fields are associated with a higher impact on scholarly debate as measured by their number of citations. In this part of the analysis, since we examine journals rather than individual papers, we are able to compare finance with all other subfields in business and management. We also examine whether impact factors rise to a greater extent for some sub-fields than others as we move from one ABS quality rating to a higher category (e.g., from $2 *$ to $\left.3^{*}\right)$.

While we are not the first to investigate the concentration of citations in finance journals (relevant prior research includes: Alexander et al., 1994; Borokhovich et al., 1994a; Chung et al., 2001), ${ }^{26}$ most previous studies focus only on the top-rated outlets. Hence, we have little extant information on citation patterns elsewhere. In addition, there is little comparison of impact factors across sub-fields to benchmark the finance journals against. Hence, our analysis provides a potentially valuable addition to the prior body of research.

There are several alternative measures of the impact factor of journals. In this section, we rely on the source-normalised impact per paper (SNIP) obtained from Scopus Journal Metrics ${ }^{27}$ as well as the h5median and h5-index from Google Scholar Metrics. ${ }^{28,}{ }^{29}$ The SNIP is defined as the number of citations

\footnotetext{
${ }^{26}$ Chung et al. (2001) show that the top two field journals in finance published more than half of all the top 100 cited papers, and the top $10 \%$ of papers garnered more than $50 \%$ of the citations.

${ }^{27}$ www.journalmetrics.com.

28 https://scholar.google.co.uk/citations?view_op=top_venues\&hl=en.

29 In unreported analysis, we re-do the analysis for the raw impact per publication (IPP), which is the number of citations per year divided by the total number of papers published in that journal over a three-year trailing window, as well as the SCImago journal rank (SJR), which further adjusts the SNIP so that a given citation also has a greater effect when it comes from a more prestigious journal. The results based on these alternative scores show a stronger impact of the top finance journals as well as a greater divide between the impact of top and lower ranked journals. Thus, our reported estimates can be regarded as conservative.
} 
per year divided by the total number of papers published in that journal over a three-year trailing window. This number is then source-normalised, i.e. modified to reflect citation patterns within each discipline so that a given citation has a greater effect in subjects where citations are less numerous. The Google Scholar measures, h5-median and h5-index, are defined as follows. The h5-index is the hindex for articles published in the last five complete years. It is the largest number $h$ such that $h$ articles published in 2010-2014 have at least $\mathrm{h}$ citations each. The h5-median for a publication is the median number of citations for the articles that make up its h5-index. The Google measures provide a different type of analysis since they include citations from unpublished works whereas those from Scopus only include citations from journals.

In line with the previous sections, we concentrate our analysis on journals listed as $2 *-4 *$ and JOD by the 2015 ABS rating list. We are particularly interested in a cross-sub-field comparison of the impact factors of finance journals vis-à-vis the journals of the other 21 business and management sub-fields of the ABS list. Hence, for these journals we obtain the journal-specific impact factors defined above. Note that in contrast to the previous sections, we do not calculate the impact factors ourselves based on an underlying sample of publications. Instead, we obtain the pre-calculated values for each journal representing the impact of the aggregate of publications in a particular outlet.

Table 7 shows the results for the SNIP and Table 8 focuses on the Google Scholar measures. The final two rows of the tables present the unweighted average impact measure across all sub-fields ${ }^{30}$ and then the rank of the impact measure for finance within the range of the 22 sub-fields. It is clear that papers published in the top journals in finance (the JOD) are very highly cited whichever of the measures in Tables 7 and 8 is employed - they have the fourth highest SNIP and the very highest Google Scholar ranks. But as we move further down the journal quality dimensions through $4 *$ to $3 *$, the citation rates fall faster in finance than in other sub-fields. For example, for the SNIP measure in Table 7, finance ranks fourth among the JOD, sixth among the $4^{*}$ journals, but $19^{\text {th }}$ and $21^{\text {st }}$ among $3^{*}$ and $2^{*}$ outlets respectively.

A particularly interesting finding emerges when we compute the ratio of the impact measure for JOD compared with those of low rankings. For example, the ratio of the SNIP for JOD relative to journals ranked as $2^{*}$ and $3^{*}$ is 2.68 in finance, the highest of all sub-fields, and compared with an average of 1.8 across all sub-fields. A similar pattern occurs when looking at the ratios for the Google measures in Table 8 as well as the ratios of the $4 *$ to $3 *$ and $2 *$ in the final columns of Tables 7 and 8.

\footnotetext{
${ }^{30}$ Several sub-fields have no JOD and therefore the comparison at this quality level can only be among subfields where there is at least one journal.
} 
What these results show collectively is that research published in the top journals in finance is very heavily cited - by the Google measures in Table 8 it is the most heavily cited of all research in business and management. But research published in almost all the lower rated journals has much lower citation rates - even for $3^{*}$ journals, which are defined by ABS as 'publish[ing] original and well executed research papers ... very selective in what they publish....[and p]apers are heavily refereed.' Hence, these patterns suggest that the top journals cite work from their own and other top journals while low ranked journals also cite work from top journals; almost no researchers in finance are citing work from the lower ranked journals so that the skewness in citation rates is much greater in finance than in any other sub-field. These findings add a new dimension to the research of Baum (2011) who demonstrates that the measured impact factors of the leading journals result from the citations of a tiny fraction of the articles they publish, the distribution of which is thus highly skewed. As a result, he argues that impact factors are a highly misleading way to evaluate journal quality and that their use in hiring, tenure and promotion decisions should cease. Impact factors measured over a short time horizon are argued to be particularly dangerous, since they favour work which is on currently fashionable topics and produces a quick hit. This occurs at the expense of 'slow burners' which have a greater effect on scholarly thinking over the longer term (Mingers, 2008). The high concentration of citations in finance speaks to the ability of those top journals to define and shape the field. It also signifies a lack of plurality in approaches and perspectives as documented in Section 2. While finance does not seem to be the only field with highly skewed citation patterns in favour of top-rated journals, it seems to show a much larger divide between the top-rated journals and the remaining outlets. Ellison (2002) noted a comparable trend in economics journals during the 1980s and 1990s, although the reverse happened for other sub-fields in business and management, with relative citation rates rising for the lowest rated journals (Starbuck, 2015, p.182).

\section{Reflection and Conclusions}

This paper has examined the publishing patterns that have emerged in academic finance research over the past two decades. We have presented new evidence on what is being published regarding the subject matter of the research, who is publishing it in terms of their country and university affiliations, and which work is being cited. With a few notable exceptions, overall, we find little diversity in the methodological approaches employed in finance journals and a lack of interdisciplinary research across quality ratings.

We first investigate the relative volumes of published work in each subject area within finance and the methodological approaches they employ. We observe that the higher rated journals publish almost nothing on insurance and are far more likely to accept corporate finance research than research on banking compared to the lower rated outlets. The vast majority of published studies at all quality levels 
adopt an empirical approach involving the analysis of secondary data; the use of case studies, interviews or experimental techniques is almost conspicuously absent in all classes of journals.

The broad similarities in subject matter and in methodology in finance publications across journal quality ratings are striking and as Gendron and Smith-Lacroix $(2015$, p.97) note, it is ironic that a discipline which espouses the benefits of diversification as one of its core principles shows a research style and agenda that is so very narrow. There are at least two potential explanations for this phenomenon. On the one hand, the lower ranked journals may have a strategy of aiming to emulate the leading journals rather than engaging in their own debates and playing to their relative strengths. On the other hand, the similarity of outputs across quality dimensions may be the result of a trickledown effect where the studies that are eventually published in $3^{*}$ and $2^{*}$ journals were initially targeted at JOD and $4^{*}$ outlets but were rejected and re-submitted to lower rated journals. The latter explanation seems particularly likely given the high rejection rates in top finance journals and the importance of journal ratings for performance measurement in universities, which provide strong incentives for academics to target their papers at the highest rated journals instead of the most suitable ones. Independent of its origin, the lack of paradigmatic diversity is dangerous because it helps to reinforce the narrowing of research agendas and methodological approaches to those preferred by the top journals, especially as the latter have little incentive to change the status quo given that they have done so well from the existing structure.

Similarly, the application of methodologies borrowed from other disciplines (aside from economics) is almost non-existent in scholarly finance research, and we were able to identify just $3 \%$ of published work as interdisciplinary. This is, perhaps, not surprising since the focus on publishing in top journals systematically under-rates interdisciplinary research, which inevitably falls between subject-specific stools, and instead privileges core, within-field knowledge (Raffles et al., 2012). Nevertheless, it is interesting that the vast majority of finance academics appear to be of the opinion that their work has nothing to learn from psychology, sociology, history or philosophy, despite the widespread belief that interdisciplinary research is highly valuable for practical problem-solving (Lowe and Phillipson, 2006) and has the potential for significant intellectual innovations, even in the sciences and medicine (Hollingsworth and Hollingsworth, 2000). Hence Napier (2007) suggests that finance should focus more on sociology and avoid the 'spurious certainties often inherent in the pricing of derivatives', a thought that might alarm most researchers in both fields.

We then investigate the trends in terms of the specific topics of studies in finance via an analysis of the author-selected keywords. This analysis illustrates the growing prominence of corporate governance research, particularly among the elite journals, and exposes an increase in research around bankruptcy, default and credit risk following the global financial crisis, suggesting that finance 
researchers are responding to the evolution of real world events when determining their research agendas. However, when combined with our other findings above, it appears that the change in research agendas has involved relatively trivial extensions of existing approaches rather than involving the complete paradigm shift in approaches and models as called for by some authors (e.g., Lo, 2011). While our analysis of the trends and patterns in finance research needs to be interpreted as mere indications of the potential future development of the field, our findings nevertheless raise important questions as to the field's influence on the finance industry, and vice versa. While Mackenzie (2006) in his reflection on the connections between scholarly finance research and the development of derivatives markets attested finance research to serve as an engine of enquiry by shaping realities rather than purely documenting empirical facts, given the recent developments in light of the financial crisis these claims need to be re-investigated, in particular with regard to the (societal) and real economic benefits that scholarly finance research may provide.

How could finance research adopt a more diverse research paradigm? One potential solution is that the elite journals embrace a more diverse research style and agenda. However, the top-rated journals in any field are likely to be very well established, publishing on popular and commonly researched topics using standard methodologies and uncontroversial theoretical frameworks. They tend to be well resourced and have the backing of prestigious bodies (Mingers and Willmott, 2013), lessening the pressure to change their current practices. Another solution is the emergence of new journals that provide a malleable alternative to the research paradigm of the established journals. While these new journals could fulfil an important role in providing an outlet for work in an emergent field that is not well positioned in any existing journals or that uses alternative research methodologies, the existence of journal rating lists and their use as an evaluation measure by research managers makes it extremely difficult for new journals to become established (Mingers and Willmott, 2013). By definition these journals will begin with no impact factor and either no journal ratings score or a very low one, encouraging a perception that they represent bad rather than unknown journals. ${ }^{31}$ Thus the incentive to publish in the top rated journals and the low chances of new, alternative outlets to reach the status of a top journal creates a funnelling effect, quashing the diversity of topics and methodologies, and leading to stagnation (Hopwood, 2008; Gendron, 2008).

\footnotetext{
${ }^{31}$ The most influential impact factor for finance journals is the Social Sciences Citation index, which is owned by Thomson Reuters, a for profit organisation which also publishes journals. In order to gain (SSCl) entry into the SSCI (aka to obtain an impact factor), any new journal must have a mock impact factor that would place it in the top half of all ranked and already included journals (By et al., 2013, p.2). This criterion creates a highly problematic catch 22 , for it would be extremely hard for any new journals to meet this threshold and yet they need inclusion in the SSCl for the prestige and publicity to enhance their status from a standing start. By and large, the only new journals standing a reasonable chance of making the grade will be those originating from the same stable as a well-established journal in the same family, and by definition these are unlikely to be in the most radical or ground-breaking areas.
} 
Our next focus is on the country of institutional affiliations of research published in finance journals at each quality level. We find that the US is pre-eminent in terms of the volume of work published in the leading journals in finance, and US authors over-achieve in terms of citations even given their high proportion of the total volume of work. Moreover, it appears that US journals are less likely to publish work by non-US based authors than journals edited in other locations. Jones and Roberts (2005) examine the authoring of articles in six US-based and six UK-based journals (in total, nine of which are in accounting, two are in finance and one spans both) over a five-year period in the late 1990s. They find that nearly two thirds of the UK journal's published articles are authored overseas while the comparable figure for the US is a mere $13 \%$. They argue that across the 12 journals, publication is highly concentrated among just five countries: the US, UK, Canada, Australia and Hong Kong.

We also show that, in addition to the country effect in the numbers of papers published in the highest rated finance journals, there exists a further dimension to the concentration of finance research and citations towards the top rated institutions, where more than half of papers published in the JOD are by authors in the Times Higher Education's Top 100 universities, and three-quarters are from the QS Top 200 MBA Schools.

Is this concentration of publications in the top journals among authors from elite institutions, especially in the US, concerning? It seems indisputable that much of the best research, however defined, is produced in the most elite institutions and being published in the highest quality journals. This is cause for celebration if such an outcome is the result of these authors producing better quality work or playing to their comparative advantage in this subject area. It may also naturally arise as evidence of the top universities' abilities to attract the brightest talent. However, it becomes more troubling if it reflects barriers to entry that prevent researchers from other institutions competing on a level playing field when producing research of comparable quality to those at the elite universities. This situation is similar to, but arguably even worse than, that in accounting, where few UK-based academics publish in the top field journals, all of which are edited in the US (Brown et al., 2007). A survey of UK accounting and finance scholars conducted by Brinn et al. (2001) confirmed the widespread belief that while the top US journals are considered to be the most prestigious of all, UK-based researchers are at a significant disadvantage due to their reduced ability to network, parochialism and a lack of interest in non-US research and gatekeeping by these journal editors.

Our final piece of analysis concerns a comparison of the average impact factors for each ABS list quality level in finance compared with other sub-fields. We show that impact factors are higher in finance than almost any of the remaining 21 sub-fields, indicating the significant effect that scholarship in this area has on the development of other research. However, more interestingly, the concentration of citations 
in finance is much more skewed towards the top journals: the ratio of citations in leading journals to other journals is almost twice that of any other sub-field.

It thus seems that publications in elite journals in finance are more prized than is the case for other subjects. This is an important issue over the longer term as it can affect the decisions of postgraduate students at the very beginning of their careers to focus on one area rather than another because of the perception they pick up from established academics that there are more 'opportunities' to publish in some sub-fields than others. For instance, Malsch \& Tessier (2015: 84), reflecting on the effect of journal rating lists embedded in university's incentive policy on their own research agendas, stress the potential of such ratings to 'fragment and politicize junior faculties' identities'. While Malsch and Tessier's reflections centre on scholars in the field of accounting, given the even stronger relative difference between the impact of publications in top finance journals and their lower rated counterparts, these tendencies are likely to be intensified for junior finance academics. In addition to the likely impact on academics' research agendas, differences in the difficulty to publish in top journals across sub-disciplines can also affect funding allocations within business schools, encouraging the growth of posts and research in areas where it is comparatively easy.

Publications in elite finance journals drive the research agendas not only within their own spheres of activity but their influence is pervasive across all finance research. Future researchers will try to pin their arguments to this mast and finance scholars appear to view citing research from anything other than the very highest rated journals as diminishing the perceived standing of their own work which would damage its chances of publication. On the other hand, even high quality research in low rated journals will struggle to gain any sort of widespread recognition by other researchers (in the unlikely event that they decide to read it). So while it seems indisputable that much of the best research, however defined, is being published in the elite journals, some truly ground-breaking research will be in the residuals. This work may be obviously brilliant to a broad-minded subject specialist if they had managed to find it, but if it is languishing in a low-rated publication outlet it is likely to remain a hidden gem. The RAE2008 Accounting and Finance sub-panel noticed this and stated in their subject report that

'world-leading work was not concentrated in a limited number of journals. Indeed, sub-panel members assessed some work in research journals in accounting and finance, that might be conventionally considered as of the highest rank, as not meeting the standards necessary to be regarded as world-leading. Conversely, sub-panel members assessed some work in research journals in accounting and finance that might be conventionally considered as being of lesser rank, as meeting the standards necessary to be regarded as world-leading.' (Ashton et al., 2009, p.201). 
This perception is supported by Starbuck (2015), who argues that the advancement of knowledge is slowed by the widespread perception that all research in top journals is outstanding while that in lowrated journals must be weak. Ranking research articles by their quality irrespective of the journals they are published in, his best estimate is that over half (57\%) of articles in the top quintile of journals by their quality rating are not in the top quintile of articles when ranked separately from the journals. In other words, a substantial amount of at best mediocre work is being published in the top journals.

Kowtowing to the elite agenda, rather than engaging in different types of research that seek answers to different questions, seems likely to ensure that lower rated universities will always finish in at best second place to the top schools. As Starbuck (2015, p.197) puts it, 'imitation is placing the imitators at a disadvantage relative to those they are imitating' and an alternative strategy of deliberate differentiation, playing to local areas of strength, might prove more successful. Rather than aiming to emulate the leading schools publishing in the leading journals, researchers should develop their own independent agendas, potentially addressing different questions, using a plurality of approaches and citing relevant and high quality work wherever it is published. This would make it possible to break out of the vicious cycle where only top journal publications are perceived to be of value in the finance area so that researchers worldwide only aim to publish there and cite no other work, thereby further privileging the elite and casting the current journal ratings in stone.

Our research has several potentially important messages for the various stakeholders involved with aspects of scholarly finance research. For Research Deans, hiring and promotions committees, we reiterate the importance of forming a judgement on the quality of work by reading and discussing it rather than purely relying on journal ratings lists. We propose that doctoral research programmes continue in the UK tradition of offering wide-ranging modules in qualitative as well as quantitative methods. While traditionally a feature of UK-based PhD programmes, there is a danger that wider exposure to other methodologies within the social sciences is becoming gradually lost as the focus increasingly narrows to advanced financial economics and econometric techniques. Such a narrowness ensures that researchers do not have the knowledge or skills to conduct surveys or experiments, and would perhaps not even entertain these approaches as possibly relevant to provide different kinds of insights to solve larger problems in finance. PhD students should be encouraged to look outwards for inspiration and ideas beyond the narrow enclaves of their specific subject matter. For individual researchers, we suggest that they are encouraged to cite relevant work in whatever outlets it is found, rather than only that in 'elite' journals. Doing so would 'level the playing field' over time, and would diminish the skewness in citations towards the top rated journals which would ultimately become selffulfilling in raising the standing of the currently lower rated outlets. 


\section{References}

Agyemang, G. and Broadbent, J. (2015) Management control systems and research management in universities: An empirical and conceptual exploration. Accounting, Auditing \& Accountability Journal 28(7), 1018-1046.

Alexander, J.C. and Mabry, R.H. (1994) Relative significance of journals, authors and articles cited in financial research. Journal of Finance 49(2), 697-712.

Ardalan, K. (2003) Theories and controversies in finance: a paradigmatic overview International Journal of Social Economics 30(1/2), 199-209.

Ardalan, K. (2000) The academic field of finance and paradigm diversity Southern Business Review 26(1), 21-31.

Arnold, T., Butler, A.W., Crack, T.F. and Altintig, A. (2003) Impact: What Influences Finance Research? Journal of Business 76(2), 343-361.

Ashton, D., Beattie, V., Broadbent, J., Brooks, C., Draper, P., Ezzamel, M., Gwilliam, D., Hodgkinson, R., Hoskin, K., Pope, P. and Stark, A. (2009). British research in accounting and finance (2001-2007): the 2008 research assessment exercise. British Accounting Review 41(4), 199-207.

Baldi, S. (1998) Normative versus social constructivist processes in the allocations of citations: a network analytic model American Sociological Review 63, 829-846.

Baum, J.A.C. (2011) Free-riding on power laws: questioning the validity of the impact factor as a measure of research quality in organizational studies. Organization 18(4), 449-466.

Beattie, V. (2005) Moving the financial accounting research front forward: the UK contribution. British Accounting Review 37, 85-114.

Beattie, V. and Goodacre, A. (2004) Publishing patterns within the UK accounting and finance academic community. British Accounting Review 36(1), 7-44.

Borokhovich, K.A., Bricker, R.J. and Simkins, B.J. (1994a) Journal communication and influence in finance research. Journal of Finance 49(2), 713-725.

Borokhovich, K.A., Bricker, R.J, and Simkins, B.J. (1994b) The streams of financial research and their interrelationships: evidence from the social sciences citation index Financial Practice and Education $4(2), 110-123$.

Borokhovich, K.A., Bricker, R.J, and Simkins, B.J. (2000) An analysis of finance journal impact factors Journal of Finance 55(3), 1457-1469.

Borokhovich, K.A., Bricker, R.J, Brunarski, K.R., and Simkins, B.J. (1995) Finance research productivity and influence Journal of Finance 50(5), 1691-1717. 
Borokhovich, K.A., Bricker, R.J, Brunarski, K.R., and Simkins, B.J. (1995) Finance research productivity and influence by topic area Journal of Financial Education 24, 8-20.

Borokhovich, K.A., Lee, A.A. and Simkins, B.J. (2015) From psychology, law, accounting and economics: measuring the influence of finance journals in social sciences Journal of Financial Education 41(3), 1-25.

Borokhovich, K.A., Lee, A.A. and Simkins, B.J. (2016) Journal influence in corporate research Managerial Finance 42(4), 376-389.

Bricker, R.J. (1993) The interdisciplinary foundations of accounting research. Working paper, Case Western Reserve University.

Brinn, T., Jones, M. and Pendlebury, M. (2001) Why do UK accounting and finance academics not publish in top US journals British Accounting Review 33, 223-232.

Brooks, C., Fenton, E., Schopohl, L. and Walker, J.T. (2017) Why does research in finance have so little impact? Working Paper, Henley Business School, University of Reading, UK.

Brown, R., Jones, M. and Steele, T. (2007) Still flickering at the margins of existence? Publishing patterns and themes in accounting and finance research over the last two decades. British Accounting Review 39, 125-151.

Burgess, T.F. and Shaw, N.E. (2010) Editorial board membership of management and business journals: A social network analysis study of the Financial Times 40. British Journal of Management 21(3), 627648.

By, R.T., Burnes, B. and Oswick, C. (2013) Creating a leading journal and maintaining academic freedom. Journal of Change Management 13(1), 1-8.

Chan, K.C., Chen, C.R. and Steiner, T.L. (2001) Research productivity of the finance profession in the Asia-Pacific region Pacific-Basin Finance Journal 9, 265-280.

Chan, K.C., Chen, C.R. and Steiner, T.L. (2002) Production in the Finance Literature, Institutional Reputation, and Labor Mobility inAcademia: A Global Perspective. Financial Management 31(4), 131156.

Chan, K.C., Fung, A., Fung, H-G. and Yau, J. (2016) A citation analysis of business ethics research: a global perspective. Journal of Business Ethics 136, 557-573.

Chan, K.C., Wong, A., and Wong, H. (2016) A complementary examination of author characteristics of finance journals Managerial Finance 42(4), 365-375.

Chung, K.H., Cox, R.A.K. and Mitchell, J.B. (2001) Citation patterns in the finance literature. Financial Management 30(3), 99-118.

Colander, D., Goldberg, M., Haas, A., Juselius, K., Kirman, A., Lux, T., and Sloth, B. (2009). The Financial Crisis and the Systemic Failure of the Economics Profession, Critical Review, 21(2-3), 249-267. 
Ellison, G. (2002) The slowdown of the economics publishing process. Journal of Political Economy 110(5), 947-993.

Gendron, Y. (2008) Constituting the academic performer: the spectre of superficiality and stagnation in academia. European Accounting Review 17(1), 97-127.

Gendron, Y. and Smith-Lacroix, J-H. (2015). The global financial crisis: Essay on the possibility of substantive change in the discipline of finance. Critical Perspectives on Accounting 30, 83-101.

Hamermesh, D.S. (2013) Six decades of top economics publishing: who and how? Journal of Economic Literature 51(1), 162-172.

Hesford, J.W., Lee, S.-H., Van der Stede, W.A. and Young, S.M. (2006) Management Accounting: A Bibliographic Study. Handbooks of Management Accounting Research, 1: 3-26.

Hollingsworth, R. And Hollingsworth, E.J. (2000) Major discoveries and biomedical research organizations: perspectives on interdisciplinary research, nurturing leadership, and integrated structures and cultures. In Weingart, P. and Stehr, N. (Eds.) Practising Interdisciplinarity, University of Toronto Press, Toronto, pp. 215-244.

Hopwood, A.G. (2008) Changing pressures on the research process: on trying to research in an age when curiosity is not enough. European Accounting Review 17(1), 87-96.

Horrigan, J. O. (1987) The Ethics of the New Finance. Journal of Business Ethics, 6, 97-110.

Jones, M., Brinn, T., and Pendlebury, M. (1996) Journal evaluation methodologies: a balanced response Omega 24(5), 607-612.

Jones, M.J. and Roberts, R. (2005) International publishing patters: an investigation of leading UK and US accounting and finance journals Journal of Business Finance and Accounting 32(5 \& 6), 1107-1140.

Judge, T.A., Cable, D.M., Colbert, A.E. and Rynes, S.L. (2007) What causes a management article to be cited: article, author or journal Academy of Management Journal 50(3), 491-506.

Kelly, M.A. and Bruestle, S. (2011) Trend of subjects published in economics journals 1969-2007. Economic Inquiry 49(3), 658-673.

Keloharju, M. (2008) What's new in finance? European Financial Management 14(3), 564-608.

Kim, E.H., Morse, A. and Zingales, L. (2006) What has mattered to economists since 1970. Journal of Economic Perspectives 20(4), 189-202.

Kim, E.H., Morse, A. and Zingales, L. (2009) Are elite universities losing their competitive edge? Journal of Financial Economics 39, 353-381. 
Klemkosky, R.C. and Tuttle, D.L. (1977) The institutional source and concentration of financial research. Journal of Finance 32(3), 901-907.

Kosnik, L. (2014) What have economists been doing for the last 50 years? A text analysis of published academic research from 1960-2010. Working Paper, University of Missouri-St. Louis.

Lee, T.A. and Williams, P.F. (1999) Accounting from the inside: legitimizing the accounting academic elite Critical Perspectives on Accounting 10(6), 867-895.

Lo, A. W. (2011) Adaptive markets and the New World Order Working Paper available at SSRN: https://ssrn.com/abstract=1977721.

Lowe, P. and Phillipson, J. (2006) reflexive interdisciplinary research: the making of a research programme on the rural economy and land use. Journal of Agricultural Economics 57(2), 165-184.

Macdonald, S. and Kam, J. (2011) The skewed few: people and papers of quality in management studies Organization 18(4), 467-475.

Macdonald, S. and Kam, J. (2007). Ring a ring o'roses: Quality journals and gamesmanship in management studies Journal of Management Studies 44(4), 640-655.

Mackenzie, D. (2006) An Engine, Not a Camera: How Financial Models Shape Markets, MIT Press, Cambridge (MA), London (UK).

Malsch, B. and Tessier, S. (2015) Journal ranking effects on junior academics: Identity fragmentation and politicization. Critical Perspectives on Accounting 26, 84-98.

May, K.O. (1967) Abuses of citational indexing Science 156, 890-892.

Merchant, K.A. (2010) Paradigms in accounting research: A view from North America. Management Accounting Research 21, 116-120.

Mingers, J. (2008) Exploring the dynamics of journal citations: modelling with s-curves. Journal of the Operational Research Society 59(8), 1013-1025.

Mingers, J. and Willmott, H. (2013) Taylorizing business school research: On the 'one best way' performative effects of journal ranking lists. Human Relations 66(8), 1051-1073.

Moed, H. (2010) Measuring contextual citation impact of scientific journals. Journal of Infometrics 4, 256-277.

Napier, R. (2007) The Anatomy of the Bear. Harriman House, Petersfield, UK.

Netter, J., Poulsen, A. and Stegmoller, M. (2009) The rise of corporate governance in corporate control research. Journal of Corporate Finance 15, 1-9. 
Raffles, I., Leydesdorff, L., O'Hare, A., Nightingale, P. and Stirling, A. (2012) How journal rankings can suppress interdisciplinary research: a comparison between innovation studies and business \& management. Research Policy 41, 1262-1282.

Rigny, D. and Barnes, D. (1980) Patterns of interdisciplinary citation in social sciences. Social Sciences Quarterly 61, 114-127.

Starbuck, W. (2015) How much better are the most prestigious journals? The statistics of academic publication. Organization Science 16(2), 180-200.

Tol, R.S.J. The Matthew effect defined and tested for the 100 most prolific economists Working Paper FNU-143 Free University, Amsterdam.

Tourish, D. and Willmott, H. (2015) In Defiance of folly: journal rankings, mindless measures and the ABS Guide Critical Perspectives on Accounting, 26, 37-46.

Sweetser, A.G. and Petry, G.H. (1981) A history of seven academic finance associations and their contributions to development of the discipline Financial Management 10(2), 46-70.

Weir, K. (2014) The Possibility of Critical Pedagogy in Finance International Journal of Liberal Arts and Social Science 2(7), 181-191.

Whitley, R. (2000) The Intellectual and Social Organization of the Sciences Oxford University Press, Oxford, $2^{\text {nd }}$ edition.

Willmott, H. (1995) Managing the academics: commodification and control in the development of university education in the UK. Human Relations 48(9), 993-1027.

Willmott, H. (2011) Journal list fetishism and the perversion of scholarship: reactivity and the ABS list. Organization 18(4), 429-442.

Wilmott, H. (2011) Listing perilously Organization 18(4), 447-448.

Woolgar, S. (1988) Knowledge and reflexivity: new frontiers in the sociology of knowledge Sage Publications, Beverley Hills, California. 
Figure 1: Word Cloud of Most Commonly Used Keywords in JOD over 1996-2015

Figure 1 depicts the 300 most commonly stated keywords of publications in finance journals classified as JOD by the 2015 ABS list, weighted by their number of occurrences over the period 1996 to 2015.

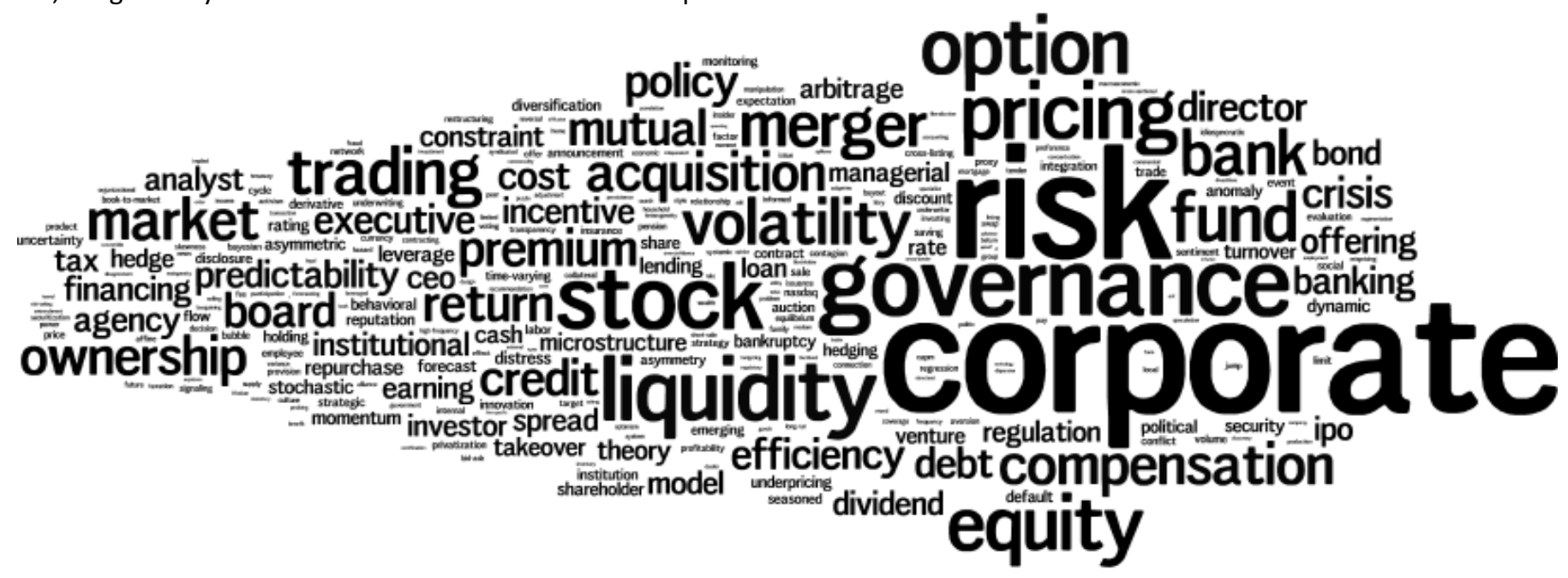

Figure 2: Word Cloud of Most Commonly Used Keywords in 4* Journals over 1996-2015

Figure 2 depicts the 300 most commonly stated keywords of publications in finance journals classified as 4* by the 2015 ABS list, weighted by their number of occurrences over the period 1996 to 2015.

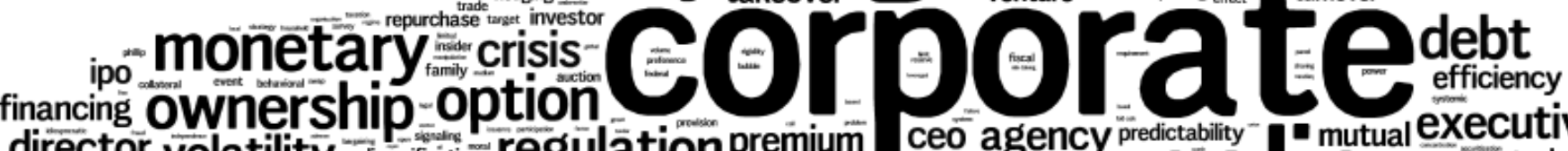
director.volatility - diversicication regulätion premium ceo agency predictability- mutual executive

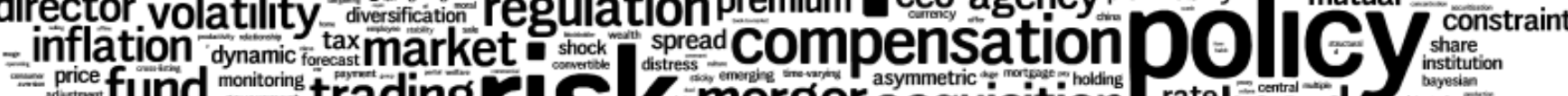

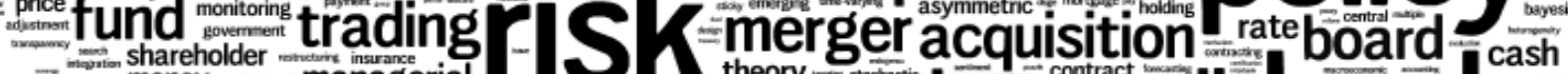

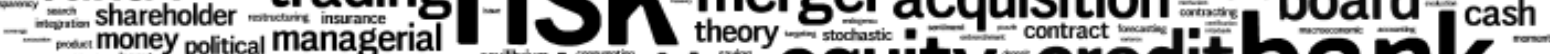

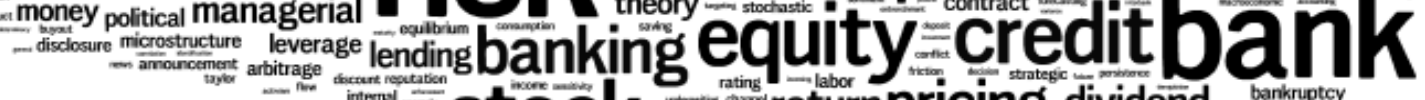
StOCK expectation returnpricing dividend barkinutcy - analyst modeclity incentive earning institution default cost 
Figure 3: Word Cloud of Most Commonly Used Keywords in 3* Journals over 1996-2015

Figure 3 depicts the 300 most commonly stated keywords of publications in finance journals classified as 3* by the 2015 ABS list, weighted by their number of occurrences over the period 1996 to 2015 .

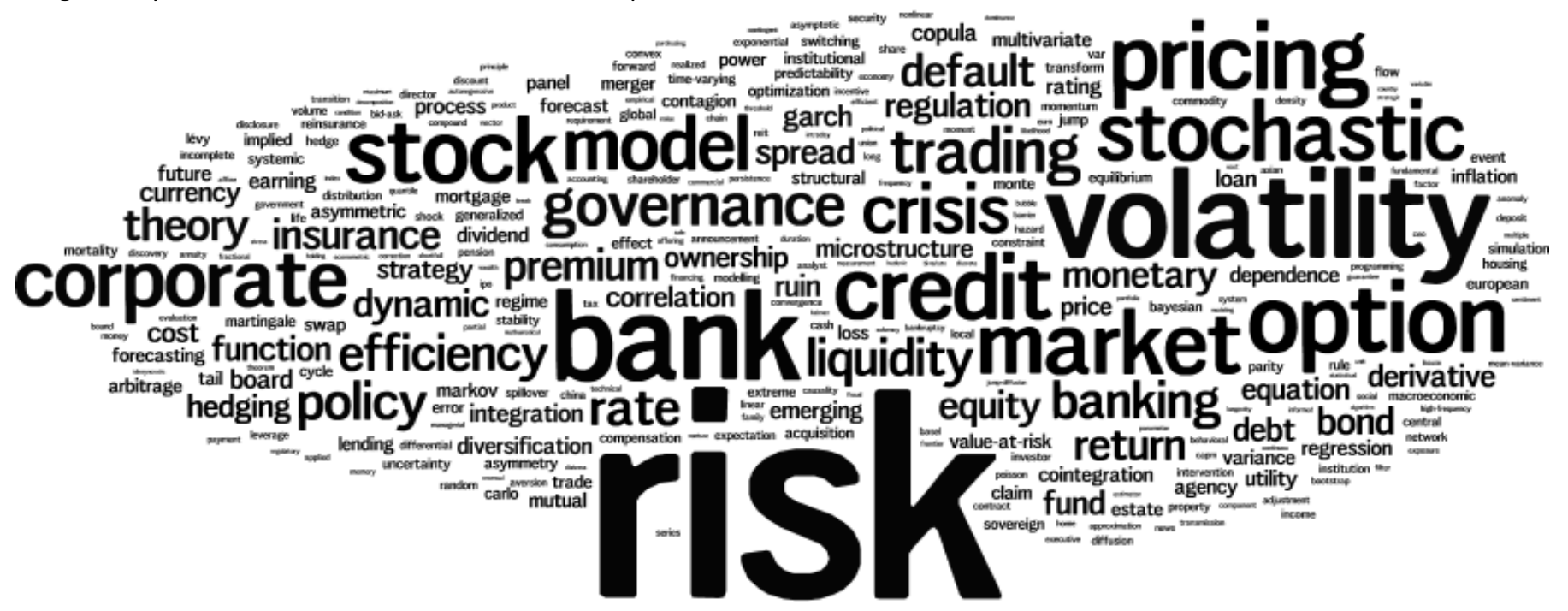

Figure 4: Word Cloud of Most Commonly Used Keywords in 2* Journals over 1996-2015

Figure 4 depicts the 300 most commonly stated keywords of publications in finance journals classified as $2 *$ by the 2015 ABS list, weighted by their number of occurrences over the period 1996 to 2015.

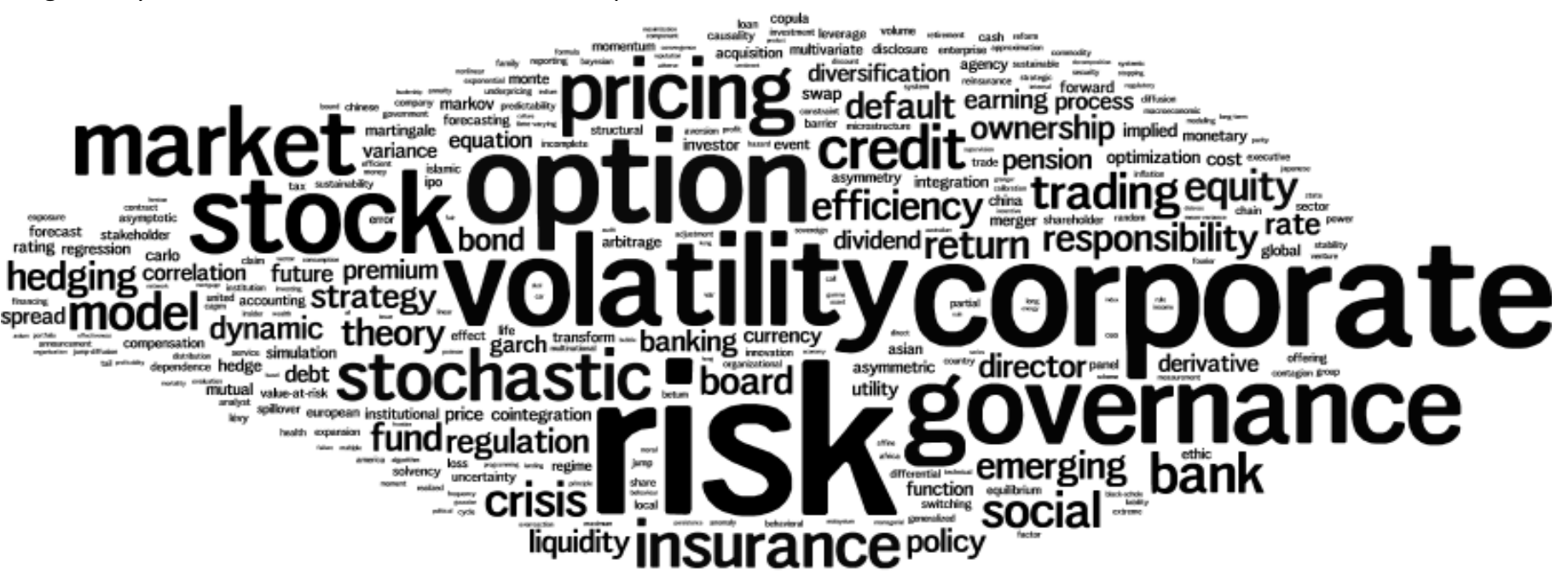




\section{Table 1: Classification of Finance Articles by Journal Rating, Subject and Methodological Approach 1996-2015}

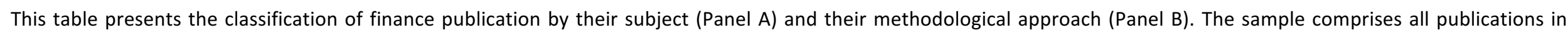

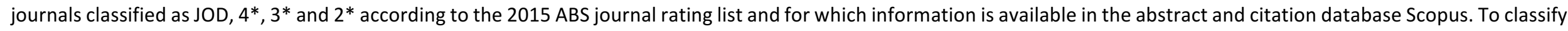

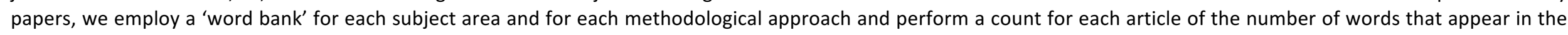
title or the abstract of each paper falling within each category. We classify a paper as being in a specific subject area or undertaking a specific methodological approach when the

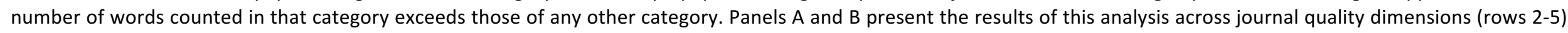
and across years (rows 6 and 7). The final row shows results across all journals and over the entire sample period spanning 1996-2015.

Panel A: Percentage of work on each subject by title and abstract word classification by journal rating

\begin{tabular}{|c|c|c|c|c|c|c|c|c|}
\hline & $\begin{array}{l}\text { Total number of } \\
\text { papers classified }\end{array}$ & $\begin{array}{r}\text { Asset } \\
\text { pricing }\end{array}$ & $\begin{array}{r}\text { Corporate } \\
\text { finance }\end{array}$ & $\begin{array}{r}\text { Corporate } \\
\text { governance }\end{array}$ & Banking & Insurance & Microstructure & $\begin{array}{r}\text { Investments and } \\
\text { Portfolio Management }\end{array}$ \\
\hline JOD & 3513 & 31.97 & 27.70 & 9.74 & 9.62 & 0.63 & 8.85 & 11.50 \\
\hline 4-star & 5304 & 26.85 & 29.26 & 12.37 & 12.52 & 0.62 & 7.01 & 11.37 \\
\hline 3-star & 13940 & 35.06 & 14.48 & 8.92 & 16.71 & 6.13 & 8.69 & 10.01 \\
\hline 2-star & 7837 & 35.72 & 15.48 & 12.59 & 13.33 & 7.29 & 5.21 & 10.39 \\
\hline All journals, 1996-2005 & 8052 & 36.50 & 19.46 & 9.04 & 12.72 & 3.39 & 8.99 & 9.90 \\
\hline All journals, 2006-2015 & 22534 & 32.36 & 18.58 & 11.09 & 14.88 & 5.36 & 7.00 & 10.73 \\
\hline All journals, all years & 30594 & 33.45 & 18.81 & 10.55 & 14.31 & 4.84 & 7.53 & 10.51 \\
\hline
\end{tabular}

Panel B: Percentage of work classified by methodological approach by journal rating

\begin{tabular}{|c|c|c|c|c|c|c|c|}
\hline & $\begin{array}{l}\text { Total number of } \\
\text { papers classified }\end{array}$ & Empirical & Economic Theory & Experimental & Qualitative & Maths Theory & $\begin{array}{r}\text { Percentage work that is } \\
\text { Interdisciplinary }\end{array}$ \\
\hline JOD & 3193 & 81.74 & 4.10 & 0.13 & 0.66 & 13.37 & 2.97 \\
\hline 4-star & 4941 & 82.13 & 4.53 & 0.18 & 0.71 & 12.45 & 3.47 \\
\hline 3-star & 15078 & 68.17 & 4.72 & 0.06 & 0.50 & 26.55 & 2.76 \\
\hline 2-star & 8487 & 68.05 & 5.34 & 0.09 & 1.00 & 25.52 & 3.10 \\
\hline All journals, 1996-2005 & 8637 & 72.33 & 5.06 & 0.06 & 0.63 & 21.93 & 2.96 \\
\hline All journals, 2006-2015 & 23052 & 71.43 & 4.70 & 0.11 & 0.70 & 23.06 & 3.01 \\
\hline All journals, all years & 31699 & 71.68 & 4.80 & 0.09 & 0.68 & 22.75 & 2.99 \\
\hline
\end{tabular}


Table 1 Continued...

Panel C: Percentage of work classified by subject area and methodological approach, all journal ratings

\begin{tabular}{|c|c|c|c|c|c|c|c|}
\hline & Asset pricing & $\begin{array}{r}\text { Corporate } \\
\text { finance }\end{array}$ & $\begin{array}{r}\text { Corporate } \\
\text { governance }\end{array}$ & Banking & Insurance & Microstructure & $\begin{array}{r}\text { Investments and } \\
\text { Portfolio Management }\end{array}$ \\
\hline Empirical & 62.91 & 81.53 & 80.78 & 72.74 & 41.81 & 81.99 & 79.74 \\
\hline Economic Theory & 6.47 & 3.45 & 5.89 & 5.41 & 8.10 & 2.46 & 3.54 \\
\hline Experimental & 0.06 & 0.16 & 0.17 & 0.12 & 0.09 & 0.06 & 0.04 \\
\hline Qualitative & 0.30 & 0.44 & 1.71 & 0.83 & 1.67 & 0.76 & 0.90 \\
\hline Maths Theory & 30.26 & 14.42 & 11.45 & 20.90 & 48.33 & 14.72 & 15.78 \\
\hline Interdisciplinary & 2.29 & 4.55 & 8.07 & 3.43 & 5.02 & 1.88 & 2.86 \\
\hline All methodologies & 100.00 & 100.00 & 100.00 & 100.00 & 100.00 & 100.00 & 100.00 \\
\hline
\end{tabular}




\section{Table 2: Top 20 Author Keywords in Finance Journals 1996-2015}

This table shows the 20 most commonly used keywords in finance publications, by journal quality dimensions (Panel A) and over time (Panel B). The percentage figures represent the proportion of occurrences of a particular keyword to the total number of occurrences across the 300 most commonly cited keywords for each subcategory. Panel $\mathrm{C}$ reports the most common words in the abstracts of finance publications classified according to their subject area and the absolute number of occurrences of each word within the publications of a subject area.

\begin{tabular}{|c|c|c|c|c|c|c|c|c|c|c|c|}
\hline \multirow{2}{*}{$\begin{array}{c}\text { Panel A } \\
1\end{array}$} & \multicolumn{2}{|c|}{ All Journals } & \multicolumn{3}{|c|}{ JoD } & \multicolumn{2}{|c|}{ 4-star } & \multicolumn{2}{|c|}{ 3-star } & \multicolumn{2}{|c|}{ 2-star } \\
\hline & risk & $4.53 \%$ & \multicolumn{2}{|c|}{ corporate } & $3.45 \%$ & corporate & $3.66 \%$ & risk & $5.12 \%$ & risk & $4.18 \%$ \\
\hline 2 & corporate & $2.38 \%$ & \multicolumn{2}{|l|}{ risk } & $3.15 \%$ & risk & $2.56 \%$ & bank & $2.22 \%$ & corporate & $3.11 \%$ \\
\hline 3 & volatility & $2.12 \%$ & \multicolumn{2}{|c|}{ governance } & $2.02 \%$ & governance & $2.33 \%$ & volatility & $2.22 \%$ & option & $2.59 \%$ \\
\hline 4 & option & $1.95 \%$ & \multicolumn{2}{|l|}{ stock } & $1.86 \%$ & policy & $2.28 \%$ & option & $1.78 \%$ & volatility & $2.53 \%$ \\
\hline 5 & bank & $1.91 \%$ & \multicolumn{2}{|l|}{ liquidity } & $1.80 \%$ & bank & $2.10 \%$ & pricing & $1.69 \%$ & governance & $2.27 \%$ \\
\hline 6 & stock & $1.84 \%$ & \multicolumn{2}{|l|}{ option } & $1.66 \%$ & equity & $1.41 \%$ & stock & $1.66 \%$ & stock & $2.26 \%$ \\
\hline 7 & governance & $1.69 \%$ & \multicolumn{2}{|l|}{ pricing } & $1.63 \%$ & liquidity & $1.39 \%$ & credit & $1.65 \%$ & market & $1.90 \%$ \\
\hline 8 & pricing & $1.63 \%$ & \multicolumn{2}{|l|}{ equity } & $1.58 \%$ & stock & $1.38 \%$ & market & $1.61 \%$ & pricing & $1.69 \%$ \\
\hline 9 & market & $1.62 \%$ & \multicolumn{2}{|l|}{ fund } & $1.43 \%$ & credit & $1.38 \%$ & stochastic & $1.52 \%$ & stochastic & $1.42 \%$ \\
\hline 10 & credit & $1.50 \%$ & \multicolumn{2}{|l|}{ trading } & $1.35 \%$ & monetary & $1.26 \%$ & corporate & $1.48 \%$ & insurance & $1.33 \%$ \\
\hline 11 & stochastic & $1.29 \%$ & \multicolumn{2}{|l|}{ merger } & $1.34 \%$ & compensation & $1.23 \%$ & model & $1.38 \%$ & credit & $1.23 \%$ \\
\hline 12 & model & $1.16 \%$ & \multicolumn{2}{|l|}{ volatility } & $1.31 \%$ & ownership & $1.16 \%$ & crisis & $1.26 \%$ & bank & $1.12 \%$ \\
\hline 13 & crisis & $1.14 \%$ & \multicolumn{2}{|l|}{ bank } & $1.30 \%$ & option & $1.15 \%$ & trading & $1.16 \%$ & model & $1.05 \%$ \\
\hline 14 & trading & $1.14 \%$ & \multicolumn{2}{|l|}{ market } & $1.21 \%$ & debt & $1.09 \%$ & governance & $1.13 \%$ & social & $1.00 \%$ \\
\hline 15 & policy & $1.08 \%$ & \multicolumn{2}{|c|}{ compensation } & $1.19 \%$ & merger & $1.07 \%$ & policy & $0.96 \%$ & trading & $0.99 \%$ \\
\hline 16 & liquidity & $1.00 \%$ & \multicolumn{2}{|c|}{ acquisition } & $1.12 \%$ & banking & $1.07 \%$ & rate & $0.95 \%$ & crisis & $0.96 \%$ \\
\hline 17 & equity & $0.93 \%$ & ownersh & & $1.11 \%$ & acquisition & $1.03 \%$ & liquidity & $0.95 \%$ & equity & $0.87 \%$ \\
\hline 18 & banking & $0.88 \%$ & return & & $1.09 \%$ & fund & $1.02 \%$ & banking & $0.94 \%$ & return & $0.84 \%$ \\
\hline 19 & efficiency & $0.87 \%$ & premium & & $1.07 \%$ & trading & $1.02 \%$ & efficiency & $0.92 \%$ & efficiency & $0.83 \%$ \\
\hline 20 & return & $0.85 \%$ & credit & & $1.04 \%$ & regulation & $1.00 \%$ & theory & $0.83 \%$ & hedging & $0.79 \%$ \\
\hline Panel B & 1996 & 2000 & & & 2001-20 & & 2006 & -2010 & & 2011-20 & \\
\hline 1 & risk & 3.2 & & risk & & $3.99 \%$ & risk & $4.30 \%$ & & risk & $4.75 \%$ \\
\hline 2 & stock & 2.3 & & option & & $2.28 \%$ & corporate & $2.56 \%$ & & corporate & $2.31 \%$ \\
\hline 3 & option & 2.1 & & corpor & rate & $2.16 \%$ & volatility & $2.14 \%$ & & volatility & $2.09 \%$ \\
\hline 4 & pricing & 2.1 & & bank & & $1.94 \%$ & option & $1.98 \%$ & & oank & $1.92 \%$ \\
\hline 5 & bank & 2.0 & & marke & & $1.89 \%$ & governance & $1.98 \%$ & & credit & $1.69 \%$ \\
\hline 6 & volatility & 1.9 & & stock & & $1.83 \%$ & stock & $1.85 \%$ & & option & $1.67 \%$ \\
\hline 7 & market & 1.8 & & volatil & & $1.81 \%$ & pricing & $1.64 \%$ & & stock & $1.62 \%$ \\
\hline 8 & rate & 1.5 & & pricing & & $1.76 \%$ & bank & $1.64 \%$ & & governance & $1.57 \%$ \\
\hline 9 & corporate & 1.5 & & goverr & nance & $1.55 \%$ & market & $1.55 \%$ & & crisis & $1.53 \%$ \\
\hline 10 & efficiency & 1.2 & & credit & & $1.26 \%$ & credit & $1.37 \%$ & & market & $1.44 \%$ \\
\hline 11 & trading & 1.2 & & stocha & astic & $1.23 \%$ & stochastic & $1.36 \%$ & & oricing & $1.40 \%$ \\
\hline 12 & stochastic & 1.2 & & tradin & & $1.21 \%$ & model & $1.19 \%$ & & tochastic & $1.18 \%$ \\
\hline 13 & model & 1.1 & & rate & & $1.12 \%$ & policy & $1.09 \%$ & & iquidity & $1.14 \%$ \\
\hline 14 & ownership & 1.0 & & model & & $1.10 \%$ & trading & $1.02 \%$ & & oolicy & $1.12 \%$ \\
\hline 15 & return & 1.0 & & liquidi & & $0.95 \%$ & insurance & $1.01 \%$ & & trading & $1.09 \%$ \\
\hline 16 & bond & 0.9 & & policy & & $0.89 \%$ & equity & $0.92 \%$ & & model & $1.08 \%$ \\
\hline 17 & banking & 0.9 & & efficie & ncy & $0.86 \%$ & liquidity & $0.82 \%$ & & equity & $0.91 \%$ \\
\hline 18 & equity & 0.9 & & bankin & & $0.81 \%$ & banking & $0.82 \%$ & & return & $0.88 \%$ \\
\hline 19 & spread & 0.8 & & crisis & & $0.80 \%$ & board & $0.81 \%$ & & banking & $0.87 \%$ \\
\hline 20 & governance & 0.8 & & equity & & $0.79 \%$ & efficiency & $0.81 \%$ & & default & $0.86 \%$ \\
\hline
\end{tabular}


Table 2 Continued ...

\begin{tabular}{|c|c|c|c|c|c|c|c|c|c|c|c|c|c|c|}
\hline \multirow{2}{*}{$\begin{array}{c}\text { Panel C } \\
1\end{array}$} & \multicolumn{2}{|c|}{ Asset pricing } & \multicolumn{2}{|c|}{ Corporate finance } & \multicolumn{2}{|c|}{ Corporate governance } & \multicolumn{2}{|c|}{ Banking } & \multicolumn{2}{|c|}{ Insurance } & \multicolumn{2}{|c|}{ Microstructure } & \multicolumn{2}{|c|}{$\begin{array}{c}\text { Investments and } \\
\text { Portfolio Management }\end{array}$} \\
\hline & stock & 10143 & risk & 4134 & corporate & 5020 & bank & 6935 & risk & 3866 & stock & 3233 & risk & 3403 \\
\hline 2 & risk & 8382 & stock & 4048 & governance & 4885 & risk & 5868 & insurance & 2526 & trading & 2839 & stock & 3076 \\
\hline 3 & return & 7353 & bank & 2979 & board & 3723 & credit & 3701 & model & 1290 & liquidity & 2701 & fund & 1987 \\
\hline 4 & volatility & 6632 & debt & 2911 & risk & 3665 & banking & 2588 & stock & 1282 & risk & 2635 & volatility & 1822 \\
\hline 5 & option & 4429 & dividend & 2419 & stock & 3133 & default & 2461 & volatility & 1272 & volatility & 2478 & model & 1502 \\
\hline 6 & model & 3802 & corporate & 2253 & ownership & 2491 & loan & 2368 & option & 1252 & market & 1928 & option & 1447 \\
\hline 7 & pricing & 3485 & option & 2027 & bank & 1902 & stock & 2197 & pension & 1195 & option & 1621 & equity & 1398 \\
\hline 8 & market & 3313 & equity & 1959 & option & 1842 & volatility & 1842 & mortality & 1008 & model & 1284 & empirical & 1383 \\
\hline 9 & price & 3306 & volatility & 1927 & empirical & 1692 & model & 1745 & policy & 988 & trade & 1249 & market & 1270 \\
\hline 10 & investor & 3200 & empirical & 1892 & shareholder & 1620 & rate & 1597 & rate & 966 & price & 1172 & price & 1170 \\
\hline 11 & trading & 3044 & policy & 1876 & volatility & 1611 & policy & 1554 & claim & 948 & spread & 1158 & forecast & 1143 \\
\hline 12 & empirical & 2820 & model & 1653 & ceo & 1594 & empirical & 1540 & life & 939 & empirical & 1112 & hedge & 1118 \\
\hline 13 & equity & 2771 & target & 1553 & company & 1465 & crisis & 1460 & premium & 888 & future & 1097 & strategy & 1082 \\
\hline 14 & returns & 2198 & cash & 1505 & model & 1464 & market & 1460 & empirical & 796 & volume & 912 & mutual & 1078 \\
\hline 15 & strategy & 2187 & country & 1422 & policy & 1314 & option & 1440 & pricing & 785 & rate & 878 & trading & 1049 \\
\hline 16 & stochastic & 2164 & earning & 1402 & compensation & 1307 & country & 1279 & insurer & 776 & bank & 825 & policy & 1044 \\
\hline 17 & dynamic & 2141 & market & 1305 & director & 1209 & insurance & 1267 & loss & 721 & policy & 763 & bank & 1013 \\
\hline 18 & future & 2059 & credit & 1274 & country & 1158 & loss & 1143 & price & 709 & pricing & 761 & rate & 979 \\
\hline 19 & rate & 2007 & ownership & 1260 & incentive & 1027 & pricing & 1107 & market & 698 & dynamic & 753 & return & 947 \\
\hline 20 & effect & 1918 & return & 1199 & market & 1009 & spread & 1102 & stochastic & 666 & monetary & 689 & country & 930 \\
\hline
\end{tabular}




\section{Table 3: Top 20 Trending Topics from Author Keywords in Finance Journals 1996 - 2015}

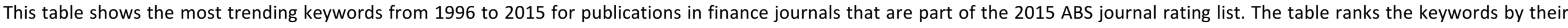

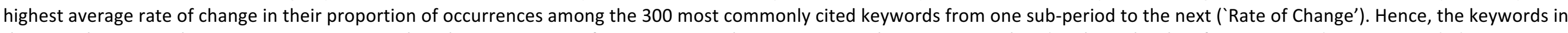

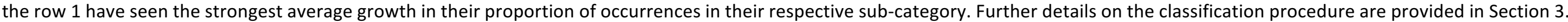

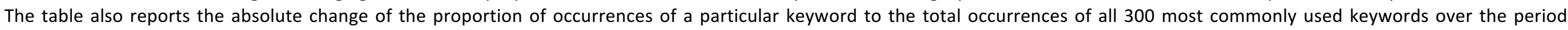
1996/2000 to 2011/15 ('Abs. Change'). Figures represent percentage points.

\begin{tabular}{|c|c|c|c|c|c|c|c|c|c|c|c|c|c|c|c|}
\hline & All Journals & $\begin{array}{l}\text { Rate of } \\
\text { Change }\end{array}$ & $\begin{array}{l}\text { Abs. } \\
\text { Change }\end{array}$ & JoD & $\begin{array}{l}\text { Rate of } \\
\text { Change }\end{array}$ & $\begin{array}{l}\text { Abs. } \\
\text { Change }\end{array}$ & 4-star & $\begin{array}{l}\text { Rate of } \\
\text { Change }\end{array}$ & $\begin{array}{l}\text { Abs. } \\
\text { Change }\end{array}$ & 3-star & $\begin{array}{l}\text { Rate of } \\
\text { Change }\end{array}$ & $\begin{array}{l}\text { Abs. } \\
\text { Change }\end{array}$ & 2-star & $\begin{array}{l}\text { Rate of } \\
\text { Change }\end{array}$ & $\begin{array}{l}\text { Abs. } \\
\text { Change }\end{array}$ \\
\hline 1 & hedge & 534.6 & 0.34 & arbitrage & 270.6 & 0.52 & lending & 297.4 & 0.61 & systemic & 104.8 & 0.36 & director & 307.0 & 0.48 \\
\hline 2 & constraint & 440.3 & 0.32 & predictability & 251.6 & 0.90 & inflation & 291.0 & 0.63 & value-at-risk & 86.6 & 0.22 & board & 270.2 & 0.70 \\
\hline 3 & social & 438.7 & 0.46 & credit & 208.7 & 1.41 & monetary & 288.5 & 1.13 & copula & 74.8 & 0.40 & governance & 262.8 & 1.85 \\
\hline 4 & copula & 425.2 & 0.36 & dynamic & 208.7 & 0.39 & money & 224.2 & 0.45 & sovereign & 69.9 & 0.31 & social & 242.2 & 0.89 \\
\hline 5 & ceo & 420.1 & 0.35 & cash & 202.2 & 0.33 & arbitrage & 219.1 & 0.23 & contagion & 68.3 & 0.31 & responsibility & 241.6 & 0.61 \\
\hline 6 & systemic & 349.7 & 0.36 & announcement & 156.3 & 0.22 & predictability & 191.2 & 0.43 & governance & 64.7 & 0.79 & pension & 161.7 & 0.56 \\
\hline 7 & contagion & 138.5 & 0.28 & premium & 154.3 & 1.25 & credit & 188.4 & 1.61 & global & 60.1 & 0.27 & utility & 154.0 & 0.33 \\
\hline 8 & predictability & 89.0 & 0.27 & default & 153.9 & 0.42 & constraint & 181.2 & 0.61 & tail & 58.2 & 0.29 & investor & 146.9 & 0.31 \\
\hline 9 & crisis & 48.5 & 0.97 & lending & 149.3 & 0.52 & premium & 129.2 & 0.76 & rating & 56.0 & 0.19 & ethic & 137.0 & 0.10 \\
\hline 10 & rating & 39.3 & 0.20 & holding & 148.0 & 0.35 & default & 128.7 & 0.55 & jump & 54.2 & 0.23 & corporate & 136.2 & 2.34 \\
\hline 11 & default & 38.6 & 0.53 & uncertainty & 142.1 & 0.28 & cycle & 126.5 & 0.40 & crisis & 51.5 & 1.13 & jump & 132.8 & 0.10 \\
\hline 12 & utility & 36.7 & 0.14 & constraint & 134.7 & 0.62 & dynamic & 124.4 & 0.45 & default & 45.7 & 0.64 & disclosure & 124.9 & 0.21 \\
\hline 13 & lending & 35.9 & 0.20 & hedge & 131.0 & 0.76 & political & 123.6 & 0.54 & utility & 44.7 & 0.15 & shareholder & 122.7 & 0.13 \\
\hline 14 & credit & 33.9 & 0.95 & asymmetric & 125.8 & 0.25 & uncertainty & 122.6 & 0.27 & liquidity & 41.0 & 0.74 & Islamic & 112.7 & 0.35 \\
\hline 15 & governance & 32.9 & 0.76 & crisis & 118.8 & 1.35 & social & 122.0 & 0.37 & dependence & 41.0 & 0.29 & merger & 108.5 & 0.28 \\
\hline 16 & dynamic & 32.8 & 0.38 & hedging & 117.1 & 0.18 & crisis & 118.0 & 1.14 & swap & 39.6 & 0.27 & optimization & 107.9 & 0.36 \\
\hline 17 & dependence & 32.7 & 0.19 & cycle & 110.3 & 0.15 & rule & 117.4 & 0.30 & Lévy & 36.0 & 0.10 & stakeholder & 107.6 & 0.13 \\
\hline 18 & liquidity & 30.6 & 0.57 & political & 109.7 & 0.56 & mortgage & 113.1 & 0.33 & institutional & 34.4 & 0.15 & monetary & 106.9 & 0.27 \\
\hline 19 & estate & 30.1 & -0.09 & social & 96.6 & 0.35 & price & 108.9 & 0.38 & forecasting & 32.2 & 0.17 & mutual & 99.7 & 0.34 \\
\hline 20 & panel & 29.7 & 0.18 & employee & 96.2 & 0.11 & disclosure & 103.1 & 0.22 & strategy & 31.5 & 0.27 & momentum & 94.2 & 0.27 \\
\hline
\end{tabular}




\section{Table 4: Top 20 Declining Topics from Author Keywords in Finance Journals 1996 - 2015}

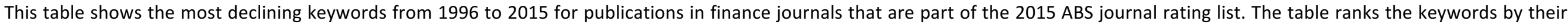

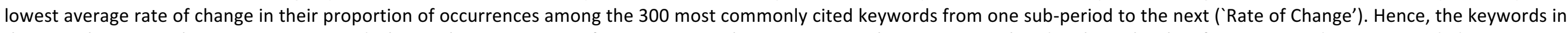

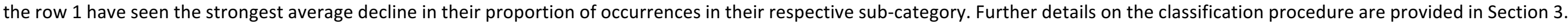

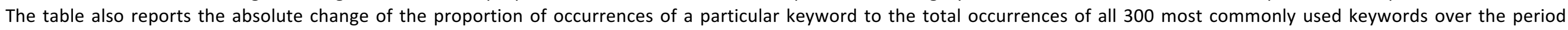
$1996 / 2000$ to 2011/15 ('Abs. Change'). Figures represent percentage points.

\begin{tabular}{|c|c|c|c|c|c|c|c|c|c|c|c|c|c|c|c|}
\hline & All Journals & $\begin{array}{l}\text { Rate of } \\
\text { Change }\end{array}$ & $\begin{array}{l}\text { Abs. } \\
\text { Change }\end{array}$ & JoD & $\begin{array}{l}\text { Rate of } \\
\text { Change }\end{array}$ & $\begin{array}{l}\text { Abs. } \\
\text { Change }\end{array}$ & 4-star & $\begin{array}{l}\text { Rate of } \\
\text { Change }\end{array}$ & $\begin{array}{l}\text { Abs. } \\
\text { Change }\end{array}$ & 3-star & $\begin{array}{l}\text { Rate of } \\
\text { Change }\end{array}$ & $\begin{array}{l}\text { Abs. } \\
\text { Change }\end{array}$ & 2-star & $\begin{array}{l}\text { Rate of } \\
\text { Change }\end{array}$ & $\begin{array}{l}\text { Abs. } \\
\text { Chang }\end{array}$ \\
\hline 1 & bid-ask & -49.5 & -0.40 & offering & -44.7 & -1.38 & offering & -43.7 & -1.31 & bid-ask & -34.3 & -0.30 & Japanese & -40.3 & $-0 . \varepsilon$ \\
\hline 2 & ruin & -36.2 & -0.55 & restructuring & -41.1 & -0.61 & bid-ask & -38.6 & -0.52 & cointegration & -34.0 & -0.56 & currency & -36.3 & $-0 . \varepsilon$ \\
\hline 3 & offering & -36.0 & -0.50 & microstructure & -38.2 & -0.77 & ownership & -35.4 & -2.09 & rate & -31.9 & -1.33 & parity & -32.7 & -0.4 \\
\hline 4 & cointegration & -32.7 & -0.48 & book-to-market & -33.5 & -0.34 & microstructure & -34.7 & -0.59 & ruin & -30.5 & -0.81 & long & -32.1 & $-0 . \Xi$ \\
\hline 5 & takeover & -31.7 & -0.37 & seasoned & -33.0 & -0.39 & derivative & -32.6 & -0.29 & incomplete & -26.1 & -0.25 & Hong Kong & -31.3 & $-0 . \Xi$ \\
\hline 6 & rate & -29.7 & -1.03 & spread & -30.8 & -1.04 & seasoned & -31.1 & -0.33 & martingale & -23.9 & -0.31 & rate & -31.1 & $-1 . c$ \\
\hline 7 & parity & -26.4 & -0.28 & nyse & -30.7 & -0.25 & offer & -30.4 & -0.31 & expectation & -23.7 & -0.32 & forward & -30.6 & -0.4 \\
\hline 8 & expectation & -25.3 & -0.23 & ownership & -29.8 & -2.01 & tender & -30.0 & -0.24 & merger & -22.7 & -0.39 & issue & -30.4 & $-0 . \Xi$ \\
\hline 9 & microstructure & -23.8 & -0.37 & Bayesian & -29.8 & -0.34 & restructuring & -29.9 & -0.50 & parity & -21.2 & -0.28 & Asian & -30.3 & -0.4 \\
\hline 10 & future & -21.2 & -0.32 & offer & -28.9 & -0.34 & future & -29.4 & -0.24 & distribution & -18.9 & -0.19 & vector & -29.9 & -0.2 \\
\hline 11 & ownership & -17.0 & -0.50 & emerging & -28.6 & -0.34 & event & -29.2 & -0.34 & claim & -17.8 & -0.23 & cointegration & -29.7 & $-0 . \varepsilon$ \\
\hline 12 & currency & -16.5 & -0.27 & tender & -26.7 & -0.25 & book-to-market & -29.1 & -0.24 & forward & -17.3 & -0.15 & integration & -28.5 & -0.4 \\
\hline 13 & garch & -15.6 & -0.25 & issue & -25.1 & -0.25 & signaling & -27.5 & -0.52 & error & -15.8 & -0.18 & share & -28.4 & $-0 . \Xi$ \\
\hline 14 & error & -15.6 & -0.16 & event & -24.8 & -0.48 & nasdaq & -26.5 & -0.86 & future & -15.4 & -0.21 & garch & -26.5 & $-0 . \epsilon$ \\
\hline 15 & spread & -15.3 & -0.33 & privatization & -24.5 & -0.22 & option & -24.4 & -1.03 & equilibrium & -15.1 & -0.25 & future & -26.2 & $-0 . \epsilon$ \\
\hline 16 & cost & -14.4 & -0.28 & repurchase & -24.3 & -0.38 & spread & -22.9 & -0.77 & acquisition & -14.0 & -0.16 & microstructure & -26.2 & $-0 . \Xi$ \\
\hline 17 & efficiency & -14.0 & -0.50 & share & -24.2 & -0.33 & stochastic & -22.1 & -0.25 & currency & -13.3 & -0.25 & offering & -25.9 & -0.4 \\
\hline 18 & martingale & -14.0 & -0.17 & dividend & -22.2 & -0.60 & certification & -20.7 & -0.24 & efficiency & -12.5 & -0.51 & announcement & -25.6 & $-0 . \overline{2}$ \\
\hline 19 & pricing & -12.8 & -0.72 & strategic & -21.4 & -0.18 & pricing & -20.5 & -0.80 & power & -12.5 & -0.14 & volume & -22.4 & $-0 . \Xi$ \\
\hline 20 & incentive & -12.8 & -0.15 & executive & -20.2 & -0.62 & reputation & -19.5 & -0.32 & mortgage & -11.6 & -0.31 & Black-Scholes & -22.0 & $-0 . \overline{2}$ \\
\hline
\end{tabular}




\section{Table 5: Country Analysis: Percentage of Publications and Citations Separated by Country / Region Based on Author Institutional Affiliations}

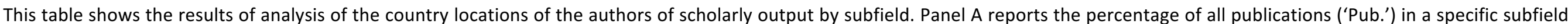

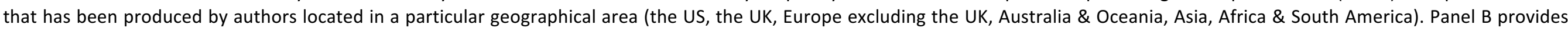

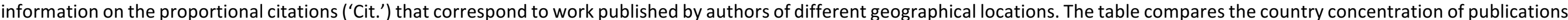

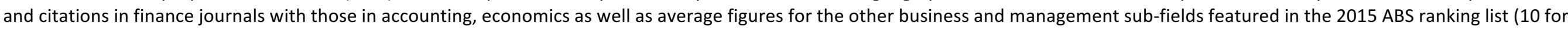

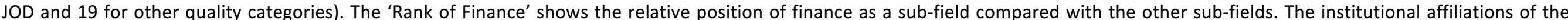

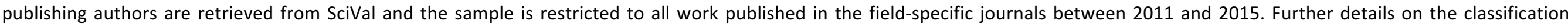
procedure are provided in Section 4.

\begin{tabular}{|c|c|c|c|c|c|c|c|c|c|c|c|c|}
\hline & \multicolumn{2}{|c|}{ US } & \multicolumn{2}{|c|}{ UK } & \multicolumn{2}{|c|}{ Europe ex UK } & \multicolumn{2}{|c|}{ Australia \& Oceania } & \multicolumn{2}{|c|}{ Asia } & \multicolumn{2}{|c|}{$\begin{array}{c}\text { Africa \& South } \\
\text { America }\end{array}$} \\
\hline & Pub. & Cit. & Pub. & Cit. & Pub. & Cit. & Pub. & Cit. & Pub. & Cit. & Pub. & Cit. \\
\hline \multicolumn{13}{|l|}{$J O D$} \\
\hline Accounting & $69.49 \%$ & $69.05 \%$ & $5.15 \%$ & $5.34 \%$ & $7.17 \%$ & $6.12 \%$ & $3.68 \%$ & $3.10 \%$ & $9.50 \%$ & $11.31 \%$ & $0.06 \%$ & $0.01 \%$ \\
\hline Economics & $63.50 \%$ & $69.98 \%$ & $6.97 \%$ & $5.68 \%$ & $17.46 \%$ & $15.95 \%$ & $1.23 \%$ & $0.84 \%$ & $6.88 \%$ & $4.40 \%$ & $0.62 \%$ & $0.71 \%$ \\
\hline Other Subfields & $58.48 \%$ & $58.32 \%$ & $6.27 \%$ & $7.49 \%$ & $15.99 \%$ & $15.29 \%$ & $2.90 \%$ & $3.16 \%$ & $10.39 \%$ & $9.50 \%$ & $0.58 \%$ & $0.32 \%$ \\
\hline \multicolumn{13}{|l|}{ 4-star } \\
\hline Finance & $59.94 \%$ & $67.86 \%$ & $6.97 \%$ & $5.36 \%$ & $15.23 \%$ & $12.97 \%$ & $2.80 \%$ & $1.93 \%$ & $10.68 \%$ & $8.80 \%$ & $0.64 \%$ & $0.20 \%$ \\
\hline Accounting & $68.39 \%$ & $69.16 \%$ & $4.90 \%$ & $4.94 \%$ & $7.22 \%$ & $5.94 \%$ & $3.06 \%$ & $2.60 \%$ & $10.43 \%$ & $11.79 \%$ & $0.04 \%$ & $0.01 \%$ \\
\hline Economics & $53.06 \%$ & $60.63 \%$ & $9.85 \%$ & $9.60 \%$ & $19.71 \%$ & $18.46 \%$ & $2.71 \%$ & $1.91 \%$ & $9.88 \%$ & $5.74 \%$ & $0.93 \%$ & $0.77 \%$ \\
\hline Other Subfields & $42.07 \%$ & $42.58 \%$ & $14.44 \%$ & $15.14 \%$ & $21.73 \%$ & $15.46 \%$ & $4.71 \%$ & $4.47 \%$ & $10.49 \%$ & $9.60 \%$ & $1.15 \%$ & $0.86 \%$ \\
\hline Rank of Finance/22 & 4 & 2 & 16 & 17 & 20 & 20 & 17 & 19 & 7 & 9 & 13 & 15 \\
\hline \multicolumn{13}{|l|}{ 3-star } \\
\hline Economics & $34.12 \%$ & $37.82 \%$ & $9.78 \%$ & $10.34 \%$ & $34.07 \%$ & $33.85 \%$ & $4.12 \%$ & $4.46 \%$ & $11.53 \%$ & $8.15 \%$ & $2.40 \%$ & $2.09 \%$ \\
\hline Other Subfields & $25.72 \%$ & $24.95 \%$ & $17.01 \%$ & $17.46 \%$ & $29.35 \%$ & $31.06 \%$ & $6.07 \%$ & $6.16 \%$ & $15.43 \%$ & $14.18 \%$ & $1.97 \%$ & $1.59 \%$ \\
\hline Rank of Finance/22 & 12 & 9 & 14 & 13 & 12 & 10 & 10 & 11 & 8 & 8 & 11 & 10 \\
\hline \multicolumn{13}{|l|}{ 2-star } \\
\hline Finance & $24.51 \%$ & $25.77 \%$ & $9.89 \%$ & $11.17 \%$ & $27.80 \%$ & $28.96 \%$ & $7.62 \%$ & $7.98 \%$ & $21.09 \%$ & $18.55 \%$ & $3.42 \%$ & $2.33 \%$ \\
\hline Accounting & $32.03 \%$ & $26.46 \%$ & $10.99 \%$ & $13.17 \%$ & $15.65 \%$ & $19.91 \%$ & $21.98 \%$ & $24.90 \%$ & $14.20 \%$ & $9.69 \%$ & $1.95 \%$ & $1.50 \%$ \\
\hline Economics & $24.61 \%$ & $26.01 \%$ & $8.77 \%$ & $9.25 \%$ & $33.63 \%$ & $36.51 \%$ & $5.50 \%$ & $5.79 \%$ & $20.32 \%$ & $15.99 \%$ & $3.48 \%$ & $3.12 \%$ \\
\hline Other Subfields & $23.42 \%$ & $24.58 \%$ & $14.70 \%$ & $14.86 \%$ & $31.57 \%$ & $32.18 \%$ & $7.39 \%$ & $7.30 \%$ & $15.51 \%$ & $13.92 \%$ & $2.67 \%$ & $2.30 \%$ \\
\hline Rank of Finance/22 & 8 & 11 & 14 & 14 & 16 & 16 & 9 & 9 & 5 & 6 & 7 & 10 \\
\hline
\end{tabular}


Table 6: Concentration of Finance Research Based on Author Institutional Affiliations

This table represents different concentration measures for finance publications (Panel $A$ ) and the citations received by these publications (Panel B) across different journal quality dimensions. The Herfindahl index is computed by squaring the proportional share of all publications (citations) within a quality category for each institution that publishes (whose work is cited) within this category and aggregating these squared values to arrive at a single index of concentration. The index is multiplied by 100 so that its values range between 0 and 100 with a higher value indicating more concentrated publications (citations) towards the most publishing (cited) institutions. The subsequent three rows state the share of publications (citations) that are apportioned to the $5 \% / 10 \% / 50 \%$ of institutions with the highest number of publications (citations). The following four rows report the share of publications (citations) that correspond to the US Ivy League Colleges, the UK universities that are part of the Russell Group, the institutions that are ranked in the top 100 of the Times Higher Education (THE) World University ranking (as of 2014-15), as well as the Top 200 business schools based on the QS MBA ranking (as of 2014-15) - the latter two comprising institutions from all around the world. The final two rows of each panel state the total number of institutions and the total number of publications (citations) that the analysis relies upon. The institutional affiliations of the publishing authors are retrieved from SciVal and the sample is restricted to all work published between 2011 and 2015. Further details on the classification procedure are provided in Section 4.

\begin{tabular}{|c|c|c|c|c|}
\hline & JOD & 4star & 3star & 2star \\
\hline \multicolumn{5}{|l|}{ Panel A: Publications } \\
\hline Herfindahl Index: & 1.01 & 0.56 & 0.22 & 0.19 \\
\hline Percentage in Top $5 \%$ Institutions by Publications: & $31.87 \%$ & $32.58 \%$ & $28.97 \%$ & $25.10 \%$ \\
\hline Percentage in Top $10 \%$ Institutions by Publications: & $47.76 \%$ & $49.47 \%$ & $44.42 \%$ & $39.53 \%$ \\
\hline Percentage in Top $50 \%$ Institutions by Publications: & $91.57 \%$ & $91.28 \%$ & $90.27 \%$ & $86.26 \%$ \\
\hline Percentage of Publications from Ivy League Colleges: & $11.06 \%$ & $7.40 \%$ & $1.55 \%$ & $2.26 \%$ \\
\hline Percentage of Publications from Russell Group Institutions: & $3.08 \%$ & $3.85 \%$ & $6.70 \%$ & $4.52 \%$ \\
\hline Percentage of Publications from THE Top 100 Universities: & $55.47 \%$ & $41.85 \%$ & $18.18 \%$ & $17.43 \%$ \\
\hline Percentage of Publications from QS MBA Top 200 Schools: & $73.72 \%$ & $59.45 \%$ & $31.95 \%$ & $28.08 \%$ \\
\hline Total number of institutions: & 329 & 638 & 1,402 & 1,348 \\
\hline Total number of publications: & 2,504 & 4,853 & 12,065 & 6,499 \\
\hline \multicolumn{5}{|l|}{ Panel B: Citations } \\
\hline Herfindahl Index: & 1.34 & 0.99 & 0.28 & 0.32 \\
\hline Percentage in Top $5 \%$ Institutions by Citations: & $37.62 \%$ & $44.79 \%$ & $34.44 \%$ & $36.05 \%$ \\
\hline Percentage in Top $10 \%$ Institutions by Citations: & $53.45 \%$ & $63.57 \%$ & $50.99 \%$ & $52.25 \%$ \\
\hline Percentage in Top $50 \%$ Institutions by Citations: & $94.98 \%$ & $97.12 \%$ & $94.27 \%$ & $94.48 \%$ \\
\hline Percentage of Citations from Ivy League Colleges: & $13.36 \%$ & $11.34 \%$ & $2.48 \%$ & $3.83 \%$ \\
\hline Percentage of Citations from Russell Group Institutions: & $2.29 \%$ & $2.80 \%$ & $6.47 \%$ & $5.05 \%$ \\
\hline Percentage of Citations from THE Top 100 Universities: & $58.21 \%$ & $51.28 \%$ & $19.59 \%$ & $22.57 \%$ \\
\hline Percentage of Citations from QS MBA Top 200 Schools: & $74.07 \%$ & $68.15 \%$ & $34.19 \%$ & $31.81 \%$ \\
\hline Total number of institutions: & 329 & 638 & 1,402 & 1,348 \\
\hline Total number of citations: & 46,803 & 61,733 & 59,089 & 15,432 \\
\hline
\end{tabular}




\section{Table 7: 2013 Source Normalised Impact Per Paper by Sub-field}

This table presents source-normalised impact factors (SNIP) for all journals of the 22 business and management subfields of the 2015 ABS journal ratings list. The SNIP is defined as the number of citations per year for all publications in a journal divided by the total number of papers published in that journal over a three-year trailing window and sourcenormalised to reflect citation patterns within each discipline so that a given citation has a greater effect in subjects where citations are less numerous. The SNIPs are obtained from Scopus Journal Metrics. The columns JOD, 4*, 3* and $2 *$ report the average SNIPs across journals in the respective sub-field. The final two rows show the ratio of the SNIP for the JOD and the $4^{*}$ journals respectively, divided by the average SNIP for $3^{*}$ and $2^{*}$ journals. The final two rows of the table present the average SNIP across all sub-fields and the rank of the SNIP for finance within the range of the 22 sub-fields. Further details on the classification procedure are provided in Section 5.

\begin{tabular}{|c|c|c|c|c|c|c|}
\hline Sub-field & JOD & $4^{*}$ & 3* & 2* & $\begin{array}{c}\text { Ratio } \\
\text { JOD:(3*+2*) }\end{array}$ & $\begin{array}{c}\text { Ratio } \\
4^{*}:\left(3^{*}+2^{*}\right)\end{array}$ \\
\hline Finance & 2.76 & 3.02 & 1.36 & 0.70 & 2.68 & 2.93 \\
\hline Accountancy & 1.83 & 2.35 & 1.21 & 0.55 & 2.08 & 2.68 \\
\hline Business History and Economic History & & 1.63 & 0.99 & 0.78 & & 1.84 \\
\hline Economics & 3.39 & 3.48 & 1.81 & 1.11 & 2.33 & 2.39 \\
\hline Entrepreneurship \& Small Business Management & & 2.55 & 1.60 & 0.88 & & 2.06 \\
\hline Ethics and CSR & 3.76 & 3.30 & 1.78 & 1.21 & 2.51 & 2.21 \\
\hline Human Resource Management and Employment & & 1.53 & 1.39 & 0.84 & & 1.37 \\
\hline International Business \& Area & 2.10 & 2.51 & 1.53 & 1.00 & 1.66 & 1.99 \\
\hline Information Management & 2.67 & 2.59 & 1.88 & 1.63 & 1.52 & 1.48 \\
\hline Innovation & & 2.45 & 1.70 & 1.11 & & 1.74 \\
\hline Management Development and Education & & 1.88 & 2.03 & 1.19 & & 1.17 \\
\hline Marketing & 0.57 & 0.59 & 0.99 & 1.01 & 0.57 & 0.59 \\
\hline Operations and Technology & 1.30 & 2.30 & 1.79 & 1.55 & 0.77 & 1.38 \\
\hline Operations Research \& Management Science & 2.23 & 3.11 & 2.10 & 1.17 & 1.36 & 1.90 \\
\hline Organisational Studies & 2.55 & 2.08 & 1.55 & 0.94 & 2.05 & 1.68 \\
\hline Psychology (General) & & 4.53 & 1.44 & 1.07 & & 3.61 \\
\hline Psychology (WOP-OB) & & 2.31 & 1.57 & 1.13 & & 1.71 \\
\hline Public Sector & & 1.76 & 1.63 & 0.98 & & 1.35 \\
\hline Regional Studies, Planning and Environment & & 1.80 & 1.81 & 1.10 & & 1.24 \\
\hline Sector Studies & & 2.63 & 1.91 & 1.15 & & 1.72 \\
\hline Social Sciences & 3.44 & 2.89 & 1.77 & 1.17 & 2.35 & 1.97 \\
\hline Strategy & 2.48 & 3.31 & 2.05 & 0.76 & 1.77 & 2.35 \\
\hline Average across sectors & 2.42 & 2.48 & 1.63 & 1.05 & 1.80 & 1.88 \\
\hline Rank of finance as a sub-field & 4 & 6 & 19 & 21 & 1 & 2 \\
\hline
\end{tabular}




\section{Table 8: 2015 Google Scholar Citation h-measure by Sub-field}

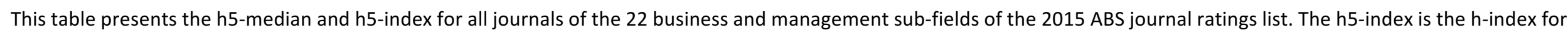

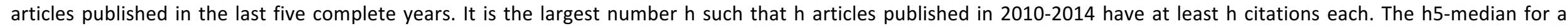

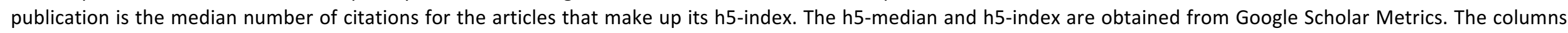

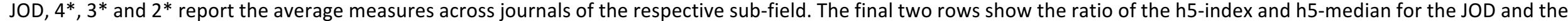

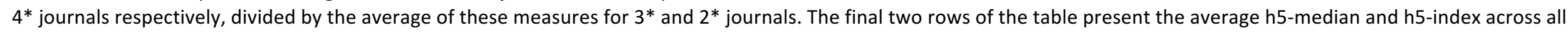
sub-fields and the rank of finance within the range of the 22 sub-fields. Further details on the classification procedure are provided in Section 5.

\begin{tabular}{|c|c|c|c|c|c|c|c|c|c|c|c|c|}
\hline \multirow[b]{2}{*}{ Sub-field } & \multicolumn{2}{|c|}{ JOD } & \multicolumn{2}{|c|}{$4 *$} & \multicolumn{2}{|c|}{ 3* } & \multicolumn{2}{|c|}{ 2* } & \multicolumn{2}{|c|}{ Ratio JOD:(3*+2*) } & \multicolumn{2}{|c|}{ Ratio $4 *:(3 *+2 *)$} \\
\hline & $\begin{array}{c}\text { h5- } \\
\text { index }\end{array}$ & $\begin{array}{c}\text { h5- } \\
\text { median }\end{array}$ & $\begin{array}{c}\text { h5- } \\
\text { index }\end{array}$ & $\begin{array}{c}\text { h5- } \\
\text { median }\end{array}$ & $\begin{array}{c}\text { h5- } \\
\text { index }\end{array}$ & $\begin{array}{c}\text { h5- } \\
\text { median }\end{array}$ & $\begin{array}{c}\text { h5- } \\
\text { index }\end{array}$ & $\begin{array}{c}\text { h5- } \\
\text { median }\end{array}$ & $\begin{array}{c}\text { h5- } \\
\text { index }\end{array}$ & $\begin{array}{c}\text { h5- } \\
\text { median }\end{array}$ & $\begin{array}{c}\text { h5- } \\
\text { index }\end{array}$ & $\begin{array}{c}\text { h5- } \\
\text { median }\end{array}$ \\
\hline Finance & 107.33 & 169.00 & 66.50 & 104.88 & 28.00 & 42.76 & 17.92 & 27.23 & 4.67 & 4.83 & 2.90 & 3.00 \\
\hline Accountancy & 52.00 & 82.00 & 46.17 & 73.17 & 23.53 & 36.60 & 12.89 & 20.22 & 2.86 & 2.89 & 2.54 & 2.58 \\
\hline Business History and Economic History & - & - & 15.00 & 21.00 & 14.80 & 21.00 & 9.00 & 12.50 & - & - & 1.26 & 1.25 \\
\hline Economics & 78.83 & 137.00 & 56.48 & 95.30 & 33.39 & 53.32 & 20.01 & 30.01 & 2.95 & 3.29 & 2.12 & 2.29 \\
\hline Entrepreneurship \& Small Business Management & - & - & 47.67 & 77.33 & 35.60 & 54.00 & 20.00 & 32.25 & - & - & 1.71 & 1.79 \\
\hline Human Resource Management and Employment & - & - & 25.00 & 35.40 & 22.78 & 34.56 & 16.47 & 25.00 & - & - & 1.27 & 1.19 \\
\hline International Business \& Area & 53.00 & 88.00 & 48.00 & 82.50 & 30.14 & 44.29 & 17.77 & 26.62 & 2.21 & 2.48 & 2.00 & 2.33 \\
\hline Information Management & 61.00 & 108.00 & 47.25 & 81.50 & 39.88 & 59.56 & 29.20 & 43.32 & 1.77 & 2.10 & 1.37 & 1.58 \\
\hline Innovation & - & - & 62.00 & 93.50 & 48.00 & 71.00 & 24.27 & 36.82 & - & - & 1.72 & 1.73 \\
\hline Management Development and Education & - & - & 37.00 & 48.00 & 30.67 & 46.67 & 19.00 & 27.63 & - & - & 1.49 & 1.29 \\
\hline Marketing & 7.00 & 8.00 & 7.50 & 9.00 & 17.13 & 25.13 & 21.11 & 33.56 & 0.37 & 0.27 & 0.39 & 0.31 \\
\hline Operations and Technology & 55.00 & 92.00 & 41.67 & 62.33 & 35.56 & 51.00 & 31.64 & 44.73 & 1.64 & 1.92 & 1.24 & 1.30 \\
\hline Operations Research \& Management Science & 59.00 & 84.00 & 58.80 & 83.60 & 30.48 & 43.48 & 20.31 & 28.38 & 2.32 & 2.34 & 2.32 & 2.33 \\
\hline Psychology (General) & - & - & 65.86 & 100.57 & 33.38 & 48.38 & 23.09 & 33.36 & - & - & 2.33 & 2.46 \\
\hline Psychology (WOP-OB) & - & - & 44.71 & 67.14 & 29.92 & 40.92 & 27.00 & 39.73 & - & - & 1.57 & 1.67 \\
\hline Public Sector & - & - & 39.33 & 55.67 & 27.56 & 40.67 & 19.30 & 28.50 & - & - & 1.68 & 1.61 \\
\hline Regional Studies, Planning and Environment & - & - & 36.00 & 58.50 & 48.25 & 72.00 & 25.75 & 36.00 & - & - & 0.97 & 1.08 \\
\hline Sector Studies & - & - & 49.60 & 79.80 & 37.10 & 56.20 & 26.57 & 37.33 & - & - & 1.56 & 1.71 \\
\hline Social Sciences & 44.33 & 83.33 & 40.67 & 66.33 & 32.44 & 48.72 & 17.87 & 26.87 & 1.76 & 2.20 & 1.62 & 1.76 \\
\hline Strategy & 71.00 & 113.00 & 71.00 & 113.00 & 26.67 & 51.00 & 20.67 & 28.33 & 3.00 & 2.85 & 3.00 & 2.85 \\
\hline Average across sectors & 59.24 & 98.00 & 44.90 & 69.79 & 31.87 & 47.98 & 21.16 & 31.15 & 2.33 & 2.52 & 1.71 & 1.76 \\
\hline Rank of finance as a sub-field & 1 & 1 & 2 & 2 & 16 & 16 & 17 & 16 & 1 & 1 & 2 & 1 \\
\hline
\end{tabular}

